\title{
Scientific and technical design and deployment of long-term subseafloor observatories for hydrogeologic and related experiments, IODP Expedition 301, eastern flank of Juan de Fuca Ridge ${ }^{1}$
}

\author{
A.T. Fisher, ${ }^{2}$ C.G. Wheat, ${ }^{2}$ K. Becker, ${ }^{2}$ E.E. Davis, ${ }^{3}$ H. Jannasch, ${ }^{4}$ D. Schroeder, ${ }^{5}$ R. Dixon, ${ }^{5}$ T.L. Pettigrew, \\ R. Meldrum, ${ }^{7}$ R. MacDonald, ${ }^{3}$ M. Nielsen, ${ }^{8}$ M. Fisk, ${ }^{10}$ J. Cowen, ${ }^{9}$ W. Bach, ${ }^{10}$ and K. Edwards ${ }^{10}$
}

\section{Chapter contents}

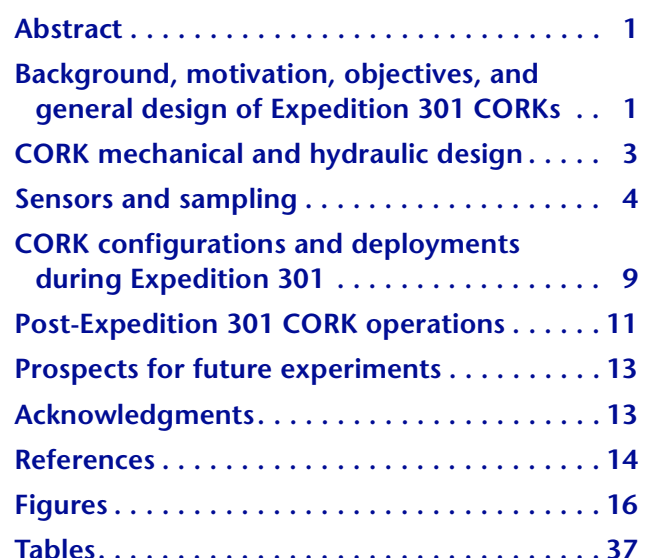

${ }^{1}$ Fisher, A.T., Wheat, C.G., Becker, K., Davis, E.E., Jannasch, H., Schroeder, D., Dixon, R., Pettigrew, T.L., Meldrum, R., McDonald, R., Nielsen, M., Fisk, M., Cowen, J., Bach, W., and Edwards, K., 2005. Scientific and technical design and deployment of long-term, subseafloor observatories for hydrogeologic and related experiments, IODP Expedition 301, eastern flank of Juan de Fuca Ridge. In Fisher, A.T., Urabe, T., Klaus, A., and the Expedition 301 Scientists, Proc. IODP, 301: College Station TX (Integrated Ocean Drilling Program Management International, Inc.). doi:10.2204/ iodp.proc.301.103.2005

'Expedition 301 Scientists' addresses.

${ }^{3}$ Pacific Geoscience Centre, Geological Survey of Canada, Canada.

${ }^{4}$ Monterey Bay Aquarium Research Institute, USA. ${ }^{5}$ Integrated Ocean Drilling Program, Texas A\&M University, USA.

${ }^{6}$ Mohr Engineering Division, Stress Engineering Services, USA.

${ }^{7}$ Natural Resources Canada, Canada.

${ }^{8}$ College of Oceanic and Atmospheric Sciences, Oregon State University, USA.

${ }^{9}$ Department of Oceanography, University of Hawaii at Manoa, USA.

${ }^{10}$ Woods Hole Oceanographic Institution, USA.

\section{Abstract}

Integrated Ocean Drilling Program (IODP) Expedition 301, on the eastern flank of the Juan de Fuca Ridge, established part of a three-dimensional network of borehole observatories (Circulation Obviation Retrofit Kits [CORKs]) in the oceanic crust. These observatories are to be used to conduct active, multidisciplinary experiments over timescales of minutes to years and length scales of meters to kilometers. The complete experimental program will comprise two IODP expeditions (the first having been Expedition 301, the second to be scheduled), an offset seismic experiment, and long-term monitoring and crosshole testing carried out by submersible and remotely operated vehicle. During Expedition 301, we replaced a preexisting CORK observatory in Hole 1026B and created and instrumented new Holes U1301A and U1301B, which penetrate 108 and $320 \mathrm{~m}$ into basement, respectively. The borehole observatories deployed during Expedition 301 share some characteristics with systems deployed during the Ocean Drilling Program but also include many improved components and novel features.

\section{Background, motivation, objectives, and general design of Expedition 301 CORKs}

Fluid flow within the seafloor influences globally important processes such as the thermal evolution of oceanic plates; alteration of the lithosphere and the chemistry of flowing fluids; establishment and maintenance of subseafloor microbial ecosystems; diagenetic, seismic, and magmatic activity along plate-boundary faults; creation of ore and hydrate deposits both on and below the seafloor; and exchange of fluids and solutes across continental margins. Although the significance of these processes has been appreciated for decades, the fundamental physical, chemical, and microbiological parameters that control and are controlled by fluid flow in the crust have remained largely unquantified.

Subseafloor hydrogeology was discussed frequently during the multiyear planning process that led to the establishment of the Integrated Ocean Drilling Program (IODP). The initial science plan for IODP includes three primary themes (International 
Working Group, 2001). Subseafloor hydrogeology is an essential part of one of these themes (the Deep Biosphere and the Subseafloor Ocean) and is important to components of the other two themes as well (Solid Earth Cycles and Geodynamics and Environmental Change, Processes, and Effects). The initial science plan highlights technological developments that are essential for IODP researchers to achieve critical scientific goals, including tools needed to establish long-term subseafloor observatories. It is appropriate that the first expedition of IODP emphasizes new kinds of borehole experiments and is helping to expand the capabilities of long-term, subseafloor observatories.

The upper oceanic crust comprises the largest aquifer on Earth. Numerous drilling, surface, and submersible surveys have explored aspects of oceanic crustal hydrogeology over the last $40 \mathrm{y}$. Critical characteristics of crustal hydrologic systems include sizes of fluid, heat, and solute fluxes; the magnitude and dynamic behavior of fluid driving forces; the nature of source and sink terms; the quantitative impacts of fluid flow on physical properties; the extent and variability of crustal storage properties; and relations among these parameters and processes. One limitation on progress in the past has been the inability to determine subseafloor conditions after the perturbing effects of drilling have dissipated. Subseafloor observatories address this need and also make it possible to maintain a measurement and sampling presence for years beyond the drilling expedition, so that induced and naturally occurring events can be monitored and interpreted.

Expedition 301 was designed to address several of the topics listed above, in part by replacing and improving two existing borehole observatory systems and establishing two new systems. The "Expedition 301 summary" chapter describes overall expedition objectives and strategy. In this paper, we describe design and deployment of subseafloor observatories. Detailed planning for these Circulation Obviation Retrofit Kit (CORK) systems began during fall 2003, immediately after the expedition was scheduled. CORK systems deployed during this expedition were intended to be used for passive monitoring and sampling and as observation points for active (perturbation) experiments that are to be initiated during a future IODP expedition and subsequent dive programs. The CORKs were designed to include instruments for pressure and temperature measurements and to house downhole and seafloor fluid samplers and microbiological growth substrate, all within vertically discrete intervals.

During Expedition 301, we planned to create two new basement holes at Site U1301, one that pene- trated the uppermost $50-100 \mathrm{~m}$ of basement and a deeper hole that penetrated $300-400 \mathrm{~m}$ of basement. These holes were to be instrumented with singleand multilevel CORK systems, respectively. We also planned to replace Ocean Drilling Program (ODP) Leg 168 CORKs in Holes 1026B and 1027C. The existing CORK body in Hole 1026B was leaking and there was no downhole instrumentation installed, whereas the CORK system in Hole 1027C was only instrumented to measure pressure and did not separate true basement rocks from overlying sediments and a sill. We ran out of time and materials to complete CORK replacement work in Hole 1027C, but we discuss plans for replacement of this system in this paper because it was an important part of Expedition 301 preparation and it will be replaced during the next drilling expedition to this area.

The Expedition 301 CORKs are similar in some ways to instruments deployed during ODP Leg 205 on the Costa Rica margin (Jannasch et al., 2003). Like those instruments, the Expedition 301 CORKs were placed inside $10^{3 / 4}$ inch casing in a reentry cone (Fig. F1). An internal $4 \frac{1}{2}$ inch casing with one or two packer elements, inflated with pressurized seawater pumped through the CORK head with the drill string, was used to isolate one or more borehole intervals at depth. Unlike the Leg 205 CORKs, the Expedition 301 CORKs did not include spool valves at the well head, and two inner casing plugs in each CORK were held in place by gravity (lower plug) and friction (upper plug), with no positive latch mechanism, in an effort to assure a complete seal and simplify later recovery. In addition to putting in situ osmotic samplers and growth substrate at depth, isolated intervals are accessed for fluid sampling by stainless steel or Tefzel (microbiologically "cleaner") tubing that penetrates through one or more casing packers and end inside small-diameter screens, with fluid sampling systems placed near the top of the CORK at the seafloor. This design concept is based on a system developed for CORKs deployed during ODP Leg 196 (Nankai Trough), although these earlier CORK systems were much larger in diameter. We arranged to have a new umbilical built for use in multilevel CORKs in Holes 1027C and U1301B, along with the microbiology sampling line for use in the lowermost intervals of these holes, and surplus umbilicals from Legs 196 and 205 were brought out for use in Holes 1026B and U1301A, respectively.

These and other design features and deployment specifics are discussed in the rest of this paper. The Expedition 301 CORKs were visited by a remotely operated vehicle (ROV) 3 weeks after the end of drilling operations, and operational results from this expedition are also described. 


\section{CORK mechanical and hydraulic design \\ General CORK configuration and operations}

CORK observatories work by hydraulically isolating discrete depth intervals, allowing formation pressure, temperature, geochemistry, and microbiology to approach an equilibrium state after the perturbation resulting from drilling has ended (Davis et al., 1992). Intervals of hydrogeologic interest to Expedition 301 studies are all in basaltic basement. The standard approach to creating a basement observatory begins with setting a reentry cone at the seafloor and installing a large-diameter conductor casing through uppermost sediments (Fig. F1). For Expedition 301, this conductor casing had a diameter of 20 inches; Holes $1026 \mathrm{~B}$ and $1027 \mathrm{C}$ were emplaced during Leg 168 and used 16 inch conductor casing. Once the cone and conductor casing are installed, the pipe is tripped, and a bottom-hole assembly is deployed with a system for drilling and/or underreaming a large-diameter hole through the rest of the sediment section and into uppermost basement. A smaller diameter casing is installed and cemented into uppermost basement (16 inch casing during Expedition $301 ; 103 / 4$ inch casing during Leg 168).

During Leg 168 in Holes 1026B and 1027C, rotary core barrel (RCB) coring commenced after the sediment was cased. During Expedition 301, we drilled into basement with a (noncoring) tricone bit to allow installation of a third casing string $\left(10^{3} / 4 \mathrm{inch}\right)$, which was cemented into place at the bottom. Once the casing cement was drilled out in Hole U1301A, no additional drilling was attempted. In contrast, Hole U1301B was subsequently deepened by RCB coring.

Once drilling, casing, and coring operations are completed, CORK casing length and locations for inflation of CORK packers in $10^{3 / 4}$ inch casing and/or open hole are selected. Each CORK is deployed on the drill string using a CORK running tool. CORK plugs and instrument strings are deployed though the drill pipe before landing the CORK in the reentry cone. When the instrument string is released and the CORK body is placed in the reentry cone, one or more CORK casing packers are inflated and the CORK running tool is released. The last standard operation is deployment of the submersible/ROV platform in the reentry cone.

\section{CORK mechanical components}

The CORK heads deployed during Expedition 301 comprise a 30 inch diameter frame built around a piece of 113/4 inch casing (Figs. F1, F2). Sampling and valve manifolds, sensor packages, data loggers, and samplers are arranged within three $1.5 \mathrm{~m}$ high bays, offset by $120^{\circ}$, and separated by steel plate bulkheads and gussets. The gussets provide strength to the CORK head and help to guide the ship's camera system and the submersible platform around the bays during installation and later operations, protecting instrumentation and valves. During Expedition 301, one bay was dedicated to monitoring and logging pressure data, one was dedicated to fluid sampling, and one was dedicated to microbiological sampling and/or auxiliary pressure monitoring or other experiments. Cutouts on the bulkheads and gussets are designed to allow a submersible or ROV to hold on for stability and leverage.

Inside and below the CORK head is the CORK body, which extends downward into the reentry cone. A seal sub (Fig. F3) is located at an appropriate depth so that it can land and seal in 103/4 inch casing near the throat of the reentry cone. Below the seal sub are crossovers and an appropriate length of $4 \frac{1}{2}$ inch casing, which extends to depth. The amount of $4 \frac{1}{2}$ inch casing that hangs below the CORK body is adjustable at sea, based on hole depth and conditions, available joint lengths, and the dimensions of other CORK components. One or more inflatable CORK casing packers are incorporated into the $4 \frac{1}{2} 2$ inch casing to allow sealing of distinct depth intervals. Additional $4 \frac{1}{2}$ inch casing can be attached below the deepest packer protect instruments if the open hole is unstable.

The $10^{3 / 4}$ inch seal sub and packers include hydraulic pass-throughs and connectors for monitoring, sampling, and inflation lines (Fig. F3), plumbed to valves and fittings within the CORK head. A $1 / 2$ inch packer inflation line is attached to the CORK running tool (used to deploy the systems) with a hose and quickconnect so that the drill string can be used to pressurize the inflation line. For systems having more than one packer, packers are connected in series and are inflated at the same time. Packer inflation lines and bodies are allowed to fill with water during initial deployment from the drillship. A check valve in the packer inflation line allows pressure to be trapped internally, and the line can be repressurized later by submersible or ROV if there is reason to suspect incomplete inflation or pressure loss within the packers.

An umbilical tubing bundle was constructed for Expedition 301 comprising four $1 / 8$ inch lines, four $1 / 4$ inch lines, and one $1 / 2$ inch line, the latter being used for packer inflation (Fig. F4). This umbilical was used for the multilevel CORK in Hole U1301B. This CORK also used a dedicated microbiological sampling tub- 
ing constructed from $1 / 2$ inch Tefzel (a variant of Teflon) hose. The single-level CORK system installed in Hole U1301A used umbilical left over from Leg 196 (six $1 / 4$ inch, one $1 / 8$ inch, and one $1 / 2$ inch lines), and that deployed in Hole 1026B used umbilical left over from Leg 205 (three $1 / 4$ inch and one $1 / 2$ inch lines). Umbilicals were attached to the outside of CORK casing with zip-ties, stainless steel banding, and duct tape. Centralizers were attached at irregular intervals to hold the $4 \frac{1}{2}$ inch casing away from the $10^{3} / 4$ inch casing and borehole wall during deployment and to protect the umbilical and miniscreens.

One challenge during earlier CORK deployments was ensuring that hydraulic lines were filled with water during deployment. Trapped air would lead to excessive compliance within the lines, which would influence pressure responses monitored at the seafloor and could lead to clogging of fluid samplers. In previous deployments that utilized umbilical lines, check valves and cap seals were used to bleed air at the time of deployment. We elected to avoid this complexity by leaving all sampling and monitoring lines open and positioning the open ends and fittings at the highest points on the lines. Valves were closed and some instruments were recovered or replaced during an ROV dive three weeks after Expedition 301.

\section{Sensors and sampling}

Expedition 301 CORKs were designed to include minimal instrumentation on the CORK head during deployment. We took this approach for several reasons. First, the CORK planning, design, construction, and testing process prior to Expedition 301 was considerably shorter than in the past and we were concerned that rushing development of sensors and instrumentation might compromise these systems. Second, leaving most of the pressure and chemical sampling instrumentation off of the CORK heads made deployment easier and allowed us to leave the lines open to purge air, as described above. We were also concerned that the CORK systems should remain sealed across most of the monitored intervals during the first 12 months after deployment so that we could determine with confidence the magnitude and sign of slight differences in formation fluid pressure relative to hydrostatic and between zones. We attached osmotic fluid samplers to the open CORK heads valves during initial deployment, but most of these instruments were recovered during subsequent ROV operations, and the associated valves were closed.

\section{Pressure measurements}

Earlier generations of CORK systems used pressure gauges and data loggers capable of measuring absolute pressure with resolution of a few kilopascals and storing several megabytes of data (Becker and Davis, this volume). Measurements were made at (user programmable) intervals of $10 \mathrm{~s}$ to 1 day. New pressure measurement and logging systems were developed for Expedition 301 CORKs and deployed by ROV after the drilling expedition. Specifications for Expedition 301 CORK pressure instrumentation are summarized in Tables $\mathbf{T} 1$ and $\mathbf{T} 2$.

Expedition 301 pressure instruments are built around Paroscientific Digiquartz absolute pressures sensors, like earlier generations of instruments. The new instruments can monitor multiple depth intervals on separate channels and have greater memory capacity, lower power consumption, and faster communication and data download rates. This permits them to sample much more frequently for longer periods than was possible in the past $(15-60 \mathrm{~s}$ versus hourly sampling in Leg 168 instruments). The new instruments also have greater pressure resolution and are less sensitive to temperature variations.

The Expedition 301 instruments store data on flash memory cards; 256 megabyte capacity was used, but greater capacity is available. In addition, a new analog-to-digital converter (ADC) for the pressure sensors provides a frequency resolution of $\sim 2 \mathrm{ppb}$ with an $800 \mathrm{~ms}$ measurement. Applied to the full dynamic range of the pressure transducers, this is equivalent to pressure resolution of $20 \mathrm{ppb}$ ( $2 \mathrm{~Pa}$ or $0.2 \mathrm{~mm}$ of water), an improvement over previous CORK instrumentation by a factor of 50 . Whether the transducers themselves are quiet at this level will be determined during coming years. This level of sensitivity could permit new studies of oceanographic (infragravity waves, tsunami, and turbulence), seismic (surface waves) and crustal hydrologic phenomena.

Hydraulic connections for the new pressure measurement and logging systems are made using customdesigned submersible-mateable connectors. Because the new pressure instruments require less power and can use smaller batteries, the sensor and logger housings are smaller and more portable. This allows the instruments to be carried to and mated with the CORK head plumbing by submersible if they are not mounted at the time of drilling and replaced later if necessary. A T-handle is used to control a valve on the pressure measurement line in the CORK head. The handle is turned $90^{\circ}$ counterclockwise from vertical to monitor the formation and $90^{\circ}$ clockwise from vertical to expose the pressure sensors to sea- 
floor pressure for a short time (during a submersible or ROV servicing visit), allowing instrument offset and drift to be checked.

\section{Temperature measurements}

Autonomous temperature sensors and data loggers were deployed in all Expedition 301 CORK systems. We elected to take this approach, rather than using a thermistor-instrumented cable attached to a central data logger, for several reasons. First, planning and cable construction would have been extremely rushed in the short time available before the start of Expedition 301, leaving little time for seasoning and testing. Also, we did not know the final hole depths or the depths that would be of greatest interest for temperature measurement, so it would have been impossible to position thermistor breakouts at the right locations. Field shortening and splicing conventional braided line is easier and more secure than modifying a multiconductor thermistor cable. It is also easier to attach braided line to plugs and sinker bars; the line can be attached with a shackle or thimble, and there is no need to penetrate the plugs for passage of conductors.

We also needed to monitor temperatures at the depths of the osmotic samplers because their sampling rates depend on the temperature-dependent viscosity of seawater. This required purchase of at least a small number of autonomous temperature loggers, but there were no suitable off-the-shelf instruments available, and tool manufacturers generally have a minimum order and significant time requirements for custom developments. We had already determined from Leg 168 measurements and subsequent CORK monitoring that temperatures in uppermost basement in this area are $\sim 62^{\circ}-65^{\circ} \mathrm{C}$ (Davis and Becker, 2002; Fisher et al., 1997; Shipboard Scientific Party, 1997), so there was no need to repeat this experiment.

We were not sure that a single vendor would be able to supply the necessary tools in time for the expedition, given the short lead time, so we contracted with two vendors to prepare temperature instruments. Antares, Datensysteme $\mathrm{GmbH}$, had previously built autonomous temperature loggers that were deployed in CORKs during Leg 205. These tools are similar in design to outrigger probes built for thermal gradient measurements on core barrels (Pfender and Villinger, 2002), but we asked Antares to design and build modified tools with a titanium pressure case, two O-ring seals, a 5 y lithium battery, and a thermistor circuit having a dynamic range of $\sim 40^{\circ}-100^{\circ} \mathrm{C}$. We anticipated formation temperatures at depth no greater than $\sim 80^{\circ}-90^{\circ} \mathrm{C}$. Choosing a limited dynamic range allowed us to maintain nominal tool resolution of $1 \mathrm{mK}$. The new tools had other specifications very similar to the older tools (Pfender and Villinger, 2002): a 16 bit ADC, nonvolatile memory for up to 64,000 readings, and a user-programmable sampling interval of $1 \mathrm{~s}$ to $255 \mathrm{~min}$. The new tools are about the size of a wide-tipped marking pen, slightly wider and longer than the older tools. The tools are programmed and operated using a through-case serial connection, with custom software run on a personal computer (PC), so the pressure cases need never be opened to operate the tools, check battery power, or access data.

The other temperature tools prepared for Expedition 301 were constructed by Onset Computer Corporation. These tools are off-the-shelf temperature loggers (HOBO model U12) modified with a titanium pressure case and longer life battery for use in the deep sea. The Onset tools have a wider temperature range than the Antares tools $\left(-40^{\circ}-100^{\circ} \mathrm{C}\right)$, temperature resolution of $0.02^{\circ}-0.1^{\circ} \mathrm{C}$, and nominal accuracy of $0.2^{\circ}-0.6^{\circ} \mathrm{C}$ across the range of anticipated CORK observatory temperatures. Like the Antares tools, the Onset tools are programmed and data are accessed using software on a PC, but the Onset tools must be opened to allow communication with a computer. The Onset tools are about the same diameter as the Antares tools, but are half as long.

Eighteen of the new Antares tools and ten Onset tools were purchased, and combinations of these tools were deployed with each CORK instrument string, as described later. Because the temperature tools arrived just before the pre-Expedition 301 port call, we did not have time to check tool calibration prior to the start of the expedition. We brought to sea a stirred-fluid temperature calibration bath (Hart Scientific model 7011) capable of maintaining temperature stability of $\pm 0.001^{\circ}-0.01^{\circ} \mathrm{C}$ over a temperature range of $0^{\circ}-100^{\circ} \mathrm{C}$ and used this system to test the temperature loggers prior to deployment. Once the bath was stable at a target temperature, absolute bath temperature was measured and logged using a National Institutes of Standards and Technologytraceable resistance temperature device probe (Hart Scientific model 1521) with an accuracy of $\pm 0.001^{\circ} \mathrm{C}$. The Onset tools were calibrated at eight temperatures in the range of $20^{\circ}-80^{\circ} \mathrm{C}$, whereas the Antares tools were calibrated at six temperatures in the range of $42^{\circ}-80^{\circ} \mathrm{C}$. Data from one typical example of each kind of tool are shown in Figure F5.

Comparison of bath and apparent tool temperatures (based on factory calibration) showed that the tools required additional calibration to achieve accuracy goals for the CORK experiments (ideally $\leq 0.01^{\circ}-$ $0.02^{\circ} \mathrm{C}$ ). The Onset tools were generally within $0.01^{\circ}-0.3^{\circ} \mathrm{C}$ of the bath temperature across the cali- 
bration range, but some tools were off by as much as $1.15^{\circ} \mathrm{C}$. The Antares tools were within $0.15^{\circ} \mathrm{C}$ of the bath temperature across the calibration range. Individual tools of both kinds exhibited systematic bias to their miscalibration, with offsets generally increasing in magnitude at higher temperatures. We crossplotted apparent tool and bath temperatures and fit second- and third-order polynomials to the data, to allow calibration corrections to be applied after data were recovered. This reduced the typical residual temperature error to $0.01^{\circ}-0.03^{\circ} \mathrm{C}$ for the Onset tools and $0.001^{\circ}-0.003^{\circ} \mathrm{C}$ for the Antares tools.

Autonomous temperature tools were deployed in two configurations with the CORK instrument strings (Fig. F6): inside polyvinyl chloride (PVC) housings containing OsmoSamplers and microbiological growth systems and on Spectra line above these systems.

\section{Fluid sampling and in situ tracer injection}

The CORK fluid sampling program comprised two approaches: (1) pumps placed at depth below the CORK seals and (2) pumps placed on the CORK head. The first kind of system allows fluid to be collected within a borehole at in situ temperature, pressure, and chemical conditions but requires opening of the CORK seal to recover the samples. The second kind of system uses valves and small-bore tubing to draw fluids from depth, making it possible for samplers on the CORK head to be recovered and redeployed using a submersible or ROV. The heart of each of these sampling systems is one or more OsmoSamplers.

OsmoSamplers are designed to sample fluid continuously for a specified time, using osmotic pressure created across a semipermeable membrane (by solutions of differing salinity) to continuously draw sample through a small-bore tubing (Jannasch et al., 2004; Theeuwes and Yum, 1976). The rate of pumping depends mainly on the osmotic gradient (held constant over the life of the instrument) and temperature (which varies slightly in crustal boreholes and is monitored continuously). Sampling systems are designed to maintain a saturated salt solution (noniodized table salt; $\mathrm{NaCl}$ ) with excess salt on one side of the membrane and distilled water on the other side. The distilled water reservoir is connected to small-bore tubing that is initially filled with distilled deionized water, thus maintaining its salt free condition. OsmoSamplers have been deployed and recovered successfully in a variety of settings, including estuaries, seamounts, seafloor spreading centers, and deep ocean boreholes (e.g., Jannasch et al., 2003;
Spinelli et al., 2002; Wheat et al., 2003, 2000). OsmoSamplers work well for long-term deployments in these settings because they require no external power and have no moving parts.

\section{Borehole OsmoSamplers}

Borehole OsmoSampler systems (Fig. F7) were designed to pass through drill pipe and the inner CORK casing, including the smallest restriction (3 inches) at the bottom plug seat. OsmoSamplers also had to be recoverable using a relatively light weight deep-sea vehicle and leave the hole accessible for future deployments. We designed the units to be light by minimizing the amount of steel in the structure, allowing the units to be lifted by one or two people on deck, and with buoyant floats during seafloor recovery. The latter is important for avoiding the timeintensive handling of a rope-pulling system from a surface ship.

An additional design constraint was that fluids were to be sampled continuously for $5 \mathrm{y}$. Samples are collected either in $1.2 \mathrm{~mm}$ internal diameter (ID) Teflon or copper tubing. Teflon tubing is used to collect fluids for dissolved ion and isotopic analyses; copper tubing is used to collect fluids for dissolved gas analyses. The number of osmotic pumps used in each downhole system was selected on the basis of earlier results, a desire to collect $\sim 3.5 \mathrm{~mL}$ of fluid per week, and practical limitations on total tubing and system length. Individual sections of tubing are coiled and joined, with as much as $912 \mathrm{~m}$ of tubing capable of collecting 1.0 L of fluid.

Downhole OsmoSampler systems were designed to survive for $5 \mathrm{y}$ at $65^{\circ}-75^{\circ} \mathrm{C}$ within hydrothermally altered formation fluid. This estimated temperature range is based on earlier studies of upper basement conditions in Hole 1026B (e.g., Davis and Becker, 2002; Fisher et al., 1997); higher temperatures are possible deeper within the crust if vigorous convection is limited to uppermost basement. The materials chosen for fabrication of downhole OsmoSamplers are compatible with deployment in formation fluids that are reduced, are depleted in dissolved oxygen and nitrate, have no measurable hydrogen sulfide and a near-neutral $\mathrm{pH}$, and contain $20 \%$ of the dissolved $\mathrm{CO}_{2}$ found in bottom seawater in this area (Wheat et al., 2004).

On the basis of these constraints and expected conditions, we used a 3 inch outer diameter (OD) highdensity polyethylene (HDPE) sleeve to protect OsmoSampler pumps and sample coils, acrylic to house the pumps, $3 / 4$ inch OD PVC schedule 80 to protect the inner diameter of the pumps and coils, a $1 / 2$ inch grooved steel rod for a strength member, HDPE and steel endcaps, and $1 / 2$ inch galvanized steel shackles 
with plastic isolators to join the units with the stainless steel bottom seal plug and sinker bar $(\mathrm{OD}=3$ inches; length $=12 \mathrm{ft}$; weight $=280 \mathrm{lb}$ in air and 250 $\mathrm{lb}$ in water). An HDPE sleeve was used rather than polycarbonate because a polycarbonate sleeve used to house the Hole 1027C OsmoSampler deployed during Leg 168 shattered during recovery, exposing the sample coils and pumps. Acrylic was used to house the membranes because its thermal expansion coefficient is similar to that of water. A steel strength member was used to provide structural support and should survive for $5 \mathrm{y}$ in a reduced environment. In fact, the CORK body that was recovered from Hole $1026 \mathrm{~B}$ after $8 \mathrm{y}$ was in excellent shape, as was the stainless steel sinker bar recovered after $3 \mathrm{y}$ from Hole 1027C (Wheat et al., 2003). Galvanized shackles were used because of their strength and corrosion resistance.

Four different kinds of OsmoSampler units were constructed for Expedition 301: gas sampling, microbiological, tracer injection, and acid addition. The number and type of each sampler deployed in each hole during Expedition 301 are discussed later. The gas sampling system includes copper tubing arranged in three coils (each $304 \mathrm{~m}$ long) and a single pump.

The microbiology units consist of four pumps, each attached to a PVC flow cell that contains four mineral samples intended to serve as growth or attachment substrate. Given the desired flow rate, the number of materials and controls to be tested, and limitations on system length, it was not possible to have the pumps filled by a distilled water reservoir of sample coils. Instead, the distilled water reservoir was enlarged so that a strong gradient could be maintained throughout the experiment between the saturated salt solution and the formation fluids drawn into the reservoir. Design of these microbiological systems, including selection of substrate, is discussed in greater detail in the next section.

Tracer injection systems were designed to help assess rates of fluid exchange within isolated intervals of the boreholes. Anticipated exchange rates in boreholes below Expedition 301 CORKs were estimated on the basis of rates determined below CORKs in Holes 1024C and 1027C (Wheat et al., 2003). We considered these earlier estimates to be lower bounds on borehole exchange rates in Holes U1301A and U1301B, perhaps by two orders of magnitude, because of the greater crustal intervals of high-permeability rock exposed in the latter holes. Each Expedition 301 tracer injection system consists of three Teflon sample coils connected to a pump with the outflow connected to three additional Teflon coils. The latter three coils were each filled with a tracer (Table T3). We used Cs, Rb, and rare earth elements
(REE) as tracers because of their low concentrations in seawater and basement formation fluids in this area, their ease of measurement using conventional analytical techniques (e.g., inductively coupled plasma-mass spectrometry [ICP-MS]), and their long-term stability within Teflon sample coils. Tracer concentrations were chosen to provide a measurable chemical anomaly for at least one of three elements given a reasonable range of volumetric exchange rates within the monitored intervals (Fig. F8). Different tracers were used in the different holes so that we could determine whether crossinterval or crosshole exchange occurred during the monitoring period.

The acid addition systems acidify samples during collection in order to minimize precipitation and microbial growth, either of which might clog the sample tubing. These systems comprise two pumps and four Teflon coils. An acid addition pump uses membranes having a smaller surface area, made of a different material, resulting in a flow rate $\sim 10 \%$ of the rate generated by the sampling pump. The outflow from the acid addition pump is attached to a Teflon coil that is filled with $40 \mathrm{~mL} / \mathrm{L}$ of subboiled $6 \mathrm{~N} \mathrm{HCl}$. This coil is joined by a tee with the three Teflon sample coils and the sample pump. The third arm of the tee is open to the formation. The sample is diluted by $10 \%$ as a result of the acid addition.

\section{CORK head OsmoSamplers}

OsmoSamplers placed on the CORK heads were designed to fit in one of three bays (Figs. F2, F9). Major issues in the design of these systems included the type and size of tubing that connects the hydraulic horizon to the seafloor, ability to maintain pressure and redox conditions of the sampled horizon, length of screened horizons, size of the bays within the CORK body, dead space between connections, longevity of hardware fixed to the CORK, metal compatibility, and fluid sampling rate.

A particular hydraulic horizon is connected to the seafloor via stainless steel tubing. Each of these stainless steel tubes is connected to a stainless steel miniscreen within the hydraulic horizon and a stainless steel union/reducer on the CORK body at the base of the chemistry bay. Several diameters of tubing were used, depending on the umbilical available. Larger ( $\geq 1 / 4$ inch) tubing is desirable for holes that are overpressured and producing because this will allow fluid production with minimal head loss or clogging. Small bore tubing ( $\leq 1 / 16$ inch) is necessary for holes that are underpressured to minimize the amount of water that must be pumped at the seafloor before sampling in situ fluids.

The fluid sampling bay of each Expedition 301 CORK can accommodate up to three CORK head Os- 
moSampler units, one for each of the three separate hydrologic intervals (Fig. F9). Even though some Expedition 301 CORKs were intended to sample fewer than three isolated intervals, three OsmoSampler locations were included on each CORK head for redundancy and consistency of design. A CORK head OsmoSampler unit starts at the connection between the plumbing from the hydraulic horizon to unions/ reducers at the base of the chemistry bay. Small bore (1/16 inch) stainless steel tubing was run from these unions/reducers to $1 / 16$ inch two-way stainless steel (Thandle) valves that are closed when horizontal and open when vertical (clockwise $90^{\circ}$ to close). These valves are connected by small-bore polyetheretherketone (PEEK) or stainless steel tubing (1/16 inch) to titanium nipples. We used different tubing materials on different CORK intervals to test the long-term stability of PEEK versus stainless steel in this environment. The nipples have a 1/16 inch hole drilled into the side. The nipples and the plastic sheet they are fastened to are designed to connect to a corresponding plate supporting an OsmoSampler. To allow OsmoSampler replacement by submersible or ROV, we designed plastic stabilizers to guide the plate into position. The plate is locked in place with a T-handle. The locked position is horizontal, rotating $90^{\circ}$ in either direction (to vertical) to unlock.

The OsmoSampler plate holds an OsmoSampler and connects it to the formation via plastic covers that fit over the small-bore hole in the titanium nipples. The holes are surrounded by two O-rings, providing a seal that holds at pressures $>500 \mathrm{kPa}$, considerably greater than differential pressures anticipated in the isolated intervals of Expedition 301 CORKs. Each OsmoSampler plate covers two titanium nipples, each of which samples the same depth horizon but uses different tubing. This allows the sampler to draw fluid from one nipple and expel fluid (outflow or waste brine) to the other nipple while maintaining in situ pressure, a capability that will be useful for CORK observatories isolating underpressured systems. We did not use this capability during Expedition 301 because we did not deploy a CORK in Hole 1027C, which is known to be underpressured.

CORK head OsmoSamplers fit within the bay and do not extend beyond the protective gussets. This limits the diameter of the sampler and the number of membranes that can be used. We were able to fit 12 membranes and $\sim 1000 \mathrm{ft}$ of $1.2 \mathrm{~mm}$ ID Teflon sample tubing within design specifications. These samplers will pump $\sim 4.0 \mathrm{~mL} /$ week at in situ temperatures. The size restriction is only necessary for deployment; samplers deployed by submersible or ROV after CORK deployment need not fit completely within the CORK head bay.

\section{Microbiological sampling and growth experiments}

The establishment of subseafloor observatories within upper oceanic crust offers an unprecedented opportunity to investigate microbial processes in basement. The CORK installation at Hole 1026B yielded some of the first evidence of active microbial communities in igneous basement of the upper oceanic crust (Cowen et al., 2003), but those samples were collected at the seafloor, after fluid had passed through long sections of casing and tubing and interacted extensively with steel and other materials (Wheat et al., 2004). CORK systems deployed during Expedition 301 include in situ growth experiments to investigate microbial colonization and alteration of minerals. Many researchers have used textural observations to investigate the role of microbiology in alteration of oceanic crust (e.g., Fisk et al., 1998, 2000; Furnes and Staudigel, 1999; Staudigel et al., 1998; Thorseth et al., 1995). The in situ microbiological growth experiments designed for Expedition 301 are intended to enable better characterization of the rate of microbial alteration of minerals and to investigate the role of mineralogy in controlling microbial alteration. These experiments comprised two kinds of systems: (1) passive experiments in which fluids are allowed to pass over polished sections of various rock or mineral samples located inside a perforated HDPE sleeve between OsmoSamplers and (2) flow cells in which fluids are pumped across rock and mineral samples using OsmoSamplers (Fig. F10).

For the passive experiments, polished samples of basalt, dunite, biotite, and pyrite, each $\sim 0.5 \mathrm{~cm}^{2}$ in exposed surface area, were mounted on plates (Fig. F10A). For each experimental apparatus, four plates were attached to a holder that fit over the inner strength member holding a set of downhole OsmoSamplers. All components of these assemblies, including screws, were composed of polycarbonate and were autoclaved prior to shipping to port.

The flow cell experiments use downhole OsmoSamplers to pump crustal fluid though chambers packed with various minerals. Each flow cell contains four chambers filled with crushed and sieved mineral samples (Table T4). Fluid enters the flow cell through a $0.12 \mathrm{~mm}$ ID Teflon inlet tube and passes through each of the mineral packages in series (in the order shown on Table T4). The flow cells were designed and assembled in pairs such that each biotic experiment is accompanied by an identical unit with the addition of a $0.2 \mu \mathrm{m}$ filter on the inlet. The filter makes the paired flow cell an abiotic control that will allow us to better distinguish between biotic and abiotic alteration textures of the minerals. Where space allowed, there is a dedicated OsmoSampler for 
each flow cell. In a few cases, two flow cells are attached to one OsmoSampler in series. In series installations, the crustal fluid passes through all four chambers of the biotic flow cell, through the filter, and into the abiotic flow cell (Fig. F10B).

The flow cell housing is constructed of PVC, and the cells are plumbed in series with $0.12 \mathrm{~mm}$ ID Teflon tubing. Minerals are packaged in plastic tubes with foam plugs at each end to act as coarse particle filters and flow diffusers. Tubing and mineral packages were autoclaved prior to deployment. Flow cell housings were rinsed in deionized water and wiped with ethanol. The flow cells were preloaded with filtered seawater $(0.2 \mu \mathrm{m})$ to ensure that they did not contain air bubbles when deployed. Natural seawater was used rather than deionized water because we wanted to achieve relatively even salinity throughout each cell for the duration of the experiment.

In addition to the downhole growth and alteration systems described above, uphole microbiological sampling capabilities were designed into the Expedition 301 CORK systems. One of the three sampling and monitoring bays on each CORK head was dedicated to microbiological and other sampling. No CORK head microbiological sampling systems were prepared for use during Expedition 301 CORKs; microbiological sampling at the seafloor will occur after formation pressures and chemistry recover from the disturbance resulting from drilling. When pressures have recovered and these CORK systems are vented for extensive periods in the future as part of longterm hydrogeologic flow experiments, there will be excellent opportunities to sample formation fluids for microbiology.

As described earlier, dedicated microbiological sampling tubing was purchased for use with CORKs to be placed in Holes U1301B and 1027C, the holes thought to provide the best opportunity to collect relatively pristine microbiological samples. This line is composed of $1 / 2$ inch Tefzel inside braided wire and an outer layer of plastic (Fig. F4). One set of passthroughs that penetrate the upper CORK seal and each of the CORK casing packers was constructed from titanium fittings and tubing so as to minimize opportunities for microbial reactions during passage of fluids from depth to the seafloor. In addition, in Hole U1301B, the section of $4 \frac{1}{2}$ inch CORK casing located next to the small-diameter screen through which microbiological samples are to be collected was sheathed in plastic shrink-wrap tubing prior to deployment. The microbiological sampling valve and fitting in the CORK heads for Holes 1026B and U1301A are connected to stainless steel sample tubing. These holes are contaminated by a relatively high area of exposure to metal, grease, and other drilling materials (particularly Hole 1026B, which includes steel casing and liner through the entire basement section), so use of the expensive, dedicated microbiological line was not justified.

\section{CORK configurations and deployments during Expedition 301}

In this section, we summarize CORK mechanical and hydraulic configurations and describe the instrument strings and CORK head samplers deployed in each borehole. The next section describes initial operations and preliminary results for the first ROV visit to the Expedition 301 CORKs during September 2004. Table T5 summarizes key characteristics of each CORK system, and schematics illustrating CORK plumbing and the subseafloor layout of each observatory are presented hole by hole. Table T6 lists varieties and depths of temperature loggers deployed in each CORK system.

\section{Hole 1026B}

The mechanical and plumbing configurations of the CORK deployed in Hole 1026B are summarized in Figures F11 and F12. Hole 1026B was drilled during Leg 168, originally to a total depth (TD) of 295.2 meters below seafloor (mbsf), $48.1 \mathrm{~m}$ subbasement (msb) (Shipboard Scientific Party, 1997). However, upper basement proved to be unstable and a piece of drill pipe was installed as a "liner" to keep the hole open. This liner extends up into the $103 / 4$ inch casing and prevents direct exposure of open hole in basement. There is clearly a good hydraulic connection between basement and the cased hole because this hole has produced copious amounts of formation fluid during the last 8 y (e.g., Cowen et al., 2003; Fisher et al., 1997; Wheat et al., 2004), but these fluids must pass between the $103 / 4$ inch casing and the liner before rising up the hole.

As a result of having the liner blocking the bottom of the hole, the Expedition 301 CORK in Hole 1026B was set with the packer in 103/4 inch casing, $100 \mathrm{~m}$ above hole TD. The instrument string was positioned almost entirely beyond the end of the $4 \frac{1}{2}$ inch CORK casing, within the $10^{3 / 4}$ inch cased hole, because there was no danger that poor hole conditions would "hang up" and prevent recovery of the instrument string (Fig. F11). The Hole 1026B CORK was deployed with a single CORK head OsmoSampler, which was subsequently recovered during September 2004 ROV operations (Fig. F13).

The instrument string deployed in this CORK contained three OsmoSampler systems, one each for gas 
sampling, acid injection and microbiological growth, and tracer injection. Each of the last two OsmoSampler systems contained a single temperature logger. No additional temperature loggers were deployed in Hole 1026B because the instrument string did not extend into basement and upper basement thermal conditions have been determined at this site during earlier drillship and CORK experiments.

A single OsmoSampling system was attached to the CORK head during deployment to monitor the open hole interval below the casing packer and was subsequently recovered during September 2004 ROV operations. All valves on the CORK head were left open on deployment and subsequently closed by the ROV.

\section{Hole U1301A}

The mechanical and plumbing configurations of the CORK deployed in Hole U1301A are shown in Figures F14 and F15. Hole U1301A was drilled to TD of $369.7 \mathrm{mbsf}, 107.5 \mathrm{~m}$ into basement. We originally attempted to set a long string of $10^{3 / 4}$ inch casing with the shoe close to TD, in the hope of making Hole U1301A the deeper basement installation. Unfortunately, we were unable to land the long casing string and elected to deploy a shorter casing string, making Hole U1301A a shallower basement installation. Casing was eventually set at $277.1 \mathrm{mbsf}(14.9 \mathrm{msb})$, leaving as much as $92.6 \mathrm{~m}$ of open $143 / 4$ inch hole below (Fig. F14). However, when we reentered Hole U1301A to check hole depth before making up the CORK, resistance was encountered at 296.2 mbsf, $<20 \mathrm{~m}$ beyond the $103 / 4$ inch casing shoe. Because hole conditions were unstable and the amount of open hole was limited, we decided to deploy a $4 \frac{1}{2}$ inch CORK casing that extended to $291.2 \mathrm{mbsf}$ ( 29.0 $\mathrm{msb}$ ).

The OsmoSampler systems we deployed comprised four sections (one of each kind of sampler) plus a sinker bar, requiring $17.4 \mathrm{~m}$ below the lower CORK plug, so we cut vertical slots into the lowermost 18 $\mathrm{m}$ of $4 \frac{1}{2}$ inch casing. The OsmoSampler systems and sinker bar were placed entirely within this slotted casing, allowing reasonably good communication with the surrounding open hole and assuring that we will be able to recover these instruments several years later. We placed six autonomous temperature loggers on the instrument string, one within each of the four OsmoSampler systems and two on the Spectra line above the lower CORK seal plug (Table T6; Fig. F14). We welded a steel rod across the opening in the "bull nose" at the end of the $4 \frac{1}{2}$ inch casing to make sure that the instrument string will not fall out of the casing, even if the line above the instruments were to part.
Because we isolated a single interval in the open hole but we used surplus umbilical tubing from Leg 196 (with six $3 / 8$ inch and one $1 / 8$ inch lines), we had redundant sampling lines available to depth. We placed four sample screens immediately below the casing packer inside the $103 / 4$ inch casing, where they are extremely well protected, and placed the other three screens in the middle of the slotted $4 \frac{1}{2}$ inch casing, surrounded by open hole (Figs. F14, F15). Sampling through the various tubings and comparing results to samples collected with downhole OsmoSamplers will help with assessing how well mixed the borehole is and whether details of tube and screen placement influence sample fluid chemistry.

The Hole U1301A CORK was designed to allow continuous monitoring of two subseafloor intervals, one that included the open hole and one that included the annulus between the $10^{3 / 4}$ inch casing and $4 \frac{1}{2}$ inch casing, to allow assessment of the integrity quality of the main CORK seal (Fig. F15). A single OsmoSampling system was attached to the CORK head during deployment, to monitor the open hole interval below the casing packer, and was subsequently recovered during September 2004 ROV operations. All CORK head valves were left open on deployment and subsequently closed by the ROV.

\section{Hole U1301B}

The mechanical and hydraulic configurations of the Hole U1301B CORK are shown in Figures F17 and F18. Hole U1301B was drilled to $582.8 \mathrm{mbsf}, 317.6 \mathrm{~m}$ into basement. Core and wireline logs indicate that we penetrated the boundary between to two lithologically distinct intervals in upper basement: an extremely rubbly and unstable upper interval, extending from the sediment/basement interface to $\sim 470$ mbsf (207.5 msb), and a more massive and layered interval below this depth. Packer experiments demonstrate that the formation surrounding the borehole is extremely permeable throughout the drilled interval, but suggest that the lower 100-120 m of the hole may be somewhat less permeable than the upper part. We selected seats for CORK packers with this information in mind, and with the intention of hydraulically separating and monitoring these two distinct intervals of upper oceanic crust.

We installed a long 103/4 inch casing string in Hole U1301B, isolating and stabilizing the uppermost 80 $\mathrm{m}$ of rubbly basement. As discussed elsewhere, we were unsuccessful in deploying our original Hole U1301B CORK system intended for use in the deeper basement hole (see the "Expedition 301 summary" and "Site U1301" chapters), which included three $4 \frac{1}{2}$ inch casing packers, but we successfully deployed 
a two-packer CORK system that allowed isolation of three crustal zones. A depth check immediately prior to CORK installation showed that the hole remained open almost to TD, giving us confidence that we could set packers in open hole and deploy OsmoSampler packages beyond the end of the $4 \frac{1}{2}$ inch CORK casing.

The Hole U1301B CORK head required modification prior to deployment. Because the Hole U1301B reentry cone settled below the mudline and a large ring of cuttings collected around the cone, we were concerned that the CORK head might sit too low below the seafloor for OsmoSamplers and valves to be accessed by an ROV or submersible during servicing visits. For this reason, the Hole U1301B CORK head was extended by $2.0 \mathrm{~m}$ by adding a short section of $4 \frac{1}{2}$ inch casing below the original CORK seal, attaching a new seal below the extension, and welding gussets around the new casing and the old seal for strength and stability (Fig. F19A).

CORK casing packers were set in open basement at $403.3 \mathrm{mbsf}(138.1 \mathrm{msb})$ and $473.5 \mathrm{mbsf}(208.3 \mathrm{msb})$, allowing isolation of three distinct basement intervals. The deeper two isolated intervals in Hole $\mathrm{U} 1301 \mathrm{~B}$ are $>33.6 \mathrm{~m}$ deeper than the TD of nearby Hole U1301A, whereas the upper interval in Hole U1301B overlaps with the monitored zone in Hole U1301A (Fig. F10 in the "Expedition 301 summary" chapter). The upper monitored interval in Hole U1301B also includes the annulus between the $4 \frac{1}{2}$ inch and $103 / 4$ inch casing and the annulus between the $103 / 4$ inch and 16 inch casing. The former was sealed with the main CORK seal (Fig. F3), and we attempted to seal the latter with cement that was pumped into the reentry cone around the CORK head near the end of operations in Hole U1301B.

The instrument string deployed below the CORK in Hole U1301B included six OsmoSampler systems: gas sampling, tracer injection, acid addition, and three for microbiological growth experiments (one of these also having acid addition) (Fig. F17). Three of these OsmoSampler systems contained autonomous temperature loggers, and ten additional temperature loggers were placed on the Spectra line above the bottom seal plug and below the top of basement (Fig. F17; Table T6). The instrument string was positioned so that all of the OsmoSamplers and the sinker bar extended beyond the end of the $4 \frac{1}{2}$ inch CORK casing, in open basement. Fluid sampling screens at the end of tubing that extended to the CORK head were positioned immediately below the casing packers in open hole (Fig. F18).

The Hole U1301B CORK was deployed with three OsmoSampler systems on the CORK head, two monitoring the middle interval, and one monitoring the deepest interval, and all valves were positioned open (Fig. F19). One of the CORK head OsmoSamplers was recovered during September 2004 ROV operations, leaving two systems to collect fluids from the middle interval, and the remaining valves on the CORK head were closed.

\section{Post-Expedition 301 CORK operations}

Three weeks after completion of Expedition 301, Holes 1026B, 1027C, U1301A, and U1301B were visited by ROV during a Thomas G. Thompson cruise (116 September 2004) to carry out the following operations:

- Inspect reentry cones for signs of leakage

- Close CORK valves left open for purging of air and surface seawater

- Install CORK pressure monitoring instrumentation

- Recover OsmoSamplers installed at the time of CORK deployments

Each instrument package (whose $\sim 60 \mathrm{~kg}$ weight in water was partially supported by releasable floatation) included a data logger, an underwater-mateable electrical connector, and pressure sensors connected to hydraulic couplers via a sheathed umbilical containing $1.5 \mathrm{~mm}$ (1/16 inch) OD stainless steel hydraulic lines (Fig. F20). These were dropped to the seafloor on an elevator (Fig. F20) from which individual units were removed with their flotation by the ROV ROPOS and carried to each of the new CORK sites. The elevator was dropped $100 \mathrm{~m}$ west of Hole U1301A; after removal of the third instrument package, the vertical mast holding the floats was removed to eliminate it as a potential hazard to submersibles or ROV tethers. At the end of the dive (spanning a total of $42 \mathrm{~h}$ on 7 and 8 September), a visit was made to Hole $1027 \mathrm{C}$ to download data recorded there since the last visit in August 2003.

\section{Operational summary}

Operations were planned for a single dive of ROPOS, although problems with hydraulic and electrical systems required two return trips of the vehicle to the deck. Outside of set-up and ROV maintenance time, the operations required $27 \mathrm{~h}$, including one round trip from the ship to the seafloor.

The pressure logging instrument deployed on the reentry cone platform in Hole 1026B was set up to monitor a single basement interval (Figs. F11, F12, F13) and is programmed to log formation and seafloor pressure at a $15 \mathrm{~s}$ interval (Tables T1, T2). The single OsmoSampler connected to sampling line 6 
was removed and recovered. All valves were closed with the exception of the three-way pressure monitoring line valve, which was left in the "monitoring" position. The upper few meters of Spectra line leading to the thermistors and OsmoSamplers was found not to be in the hole in the CORK head, and the top plug was hanging just over rim of the reentry cone. Although initially taut, the line went slack after picking up the top plug. The line could not be fed into the hole, so the plug was left on the reentry cone platform beside the CORK microbiology sampling bay. No sign of leakage from the top of the hole was observed and the differential pressure signal recorded during deployment and downloaded at the end of operations at this site looks clean (Fig. F21), so it is likely that the lower CORK plug is properly seated and sealed.

Connections to two monitoring intervals were made in Hole U1301A (Figs. F14, F15, F16); again, the instrument was placed on the reentry cone platform. Data from the formation sensors and a seafloor pressure sensor were set to record at $1 \mathrm{~min}$ intervals (Tables T1, T2). Unfortunately, no response via the RS-422 communications link was received from the logger after it was installed; a download of initial data was not possible, and the overall integrity of the seals in this CORK system could not be assessed. As in Hole 1026B, the upper CORK plug was hanging outside the CORK head, although this time the ROV was able to place the upper plug in position. There was no visible sign of leakage (e.g., shimmering water), and it seems likely that the installation is sealed. It is thought that the data logger is functioning properly because it passed deck testing prior to deployment, but we are preparing a replacement logger to be deployed by submersible in September 2005. The single OsmoSampler deployed during the drilling expedition (connected to sampling line 6 on the CORK head) was recovered, and all valves were closed except for the two pressure monitoring valves.

The reentry cone in Hole U1301B is located $>1 \mathrm{~m}$ below the seafloor. The CORK head was modified during Expedition 301 to raise it by $2 \mathrm{~m}$ in order to allow for the positioning of the cone below the seafloor. Nevertheless, the depth of the cone and the added height of the cuttings pile made the pressure logging package difficult to reach when it was placed on the reentry cone platform, so it was positioned just outside the crest of the cuttings. Connections to three monitoring intervals were made at this site (Figs. F17, F18, F19). As in Hole U1301A, data from these and a seafloor pressure sensor are being recorded at $1 \mathrm{~min}$ intervals (Tables T1, T2). Also as in Hole U1301A, no response via the communications link was received from the logger and the overall in- tegrity of the seals of this CORK system could not be assessed directly. No signs of fluid leakage were visible and it seems likely that the $103 / 4$ inch casing is sealed to the formation at depth, in this instance by a combination of sediment collapse around the 16 inch casing string and cement pumped into the reentry cone near the end of Expedition 301. The cause for the lack of communications is similarly unknown, and this logging system will also be replaced in September 2005. One of the three CORK head OsmoSamplers deployed during the drilling expedition, monitoring the deepest crustal interval, was recovered, and the other two were left in place. All valves were closed except for the two pressure monitoring valves and those servicing the remaining two OsmoSamplers.

The visit to Hole 1027C, first instrumented in 1996 and operating continuously since, went according to plan. The cone sank in this hole much in the way that the one in Hole U1301B did, but here the main casing string was cemented in with the assembly held above the seafloor. Thus, in contrast to the nearly buried reentry cone in U1301B, the cone and mud skirt in Hole 1027C looms well above the local sediment surface. An underwater connection was made to the Hole 1027C data logger, and the most recently acquired data were downloaded.

\section{Preliminary results}

The combination of laboratory tests and initial data from the new pressure ADC and logging system installed in Hole 1026B show that the units have met or exceeded all design goals (Fig. F21). Power dissipation is very low; this will allow many years of operation at much higher sampling frequency than was possible with the previous generation of CORK pressure logging systems (Tables T1, T2). Pressure resolution is also much higher than with earlier systems. Figure F21A shows the latter part of the pressure record during deployment, from the time the Hole 1026B instrument was dropped to the seafloor to the time the hydraulic coupler was mated to the CORK. Values recorded for the two sensors track one another to within $0.5 \mathrm{kPa}$ over the full range of pressure and temperature from on deck to the seafloor $\left(0.1-27 \mathrm{MPa} ; 18^{\circ}-1.8^{\circ} \mathrm{C}\right)$. A sense of instrument resolution can be gained with the detailed view in Figure F21B. Pressure resolution and noise are indicated by the comparison of differences between sequential values between the two sensors. More detailed analysis of recovered data shows coherent variations between sensors at a $\sim 60 \mathrm{~s}$ period below a level of 0.01 $\mathrm{kPa}$.

Data recorded at the time the instrument was coupled to the CORK head showed an initial $42 \mathrm{kPa}$ of 
excess fluid pressure and then a relative decline of 1 $\mathrm{kPa}$ during the $20 \mathrm{~min}$ between coupling and data download (Fig. F21C). This excess pressure comprises a combination of the natural state of basement fluid and the anomalously warm and buoyant state of the hole that had been discharging basement fluid through the various ports open since installation. The pressure decline results from a combination of the initial decline in anomalous thermal buoyancy following closure of the valves and the changing tidal pressure differential. Judging from the magnitude of the excess pressure and the quiet nature of the formation signal, the quality of the seal in Hole 1026B appears to be excellent.

The data recovered from Hole 1027C bring the total history of continuous monitoring at this site to $>8 \mathrm{y}$. Pressures recorded at the seafloor show signals from tides, weather, oceanographic mesoscale eddies, and seasonal wind-driven oscillations. This information (which constrains water mass) will be used in conjunction with satellite altimetry data (which constrains sea-surface elevation) to investigate ocean circulation processes. The formation pressure record includes response to seafloor loading over the broad oceanographic frequency band, as well as co- and postseismic strain signals associated with events on the Nootka fault in 1996 and the Juan de Fuca Ridge axis in 1999. The data collected this trip include what may be a formation pressure response to an Mw 5.8 earthquake $\sim 200 \mathrm{~km}$ to the north on the Nootka fault on 15 July 2004. In addition, there appear to be significant pressure transients associated with Expedition 301 drilling, casing, and other activities (Fig. F21D). There is an overall increase in pressure in Hole 1027C during operations in Holes U1301A and U1301B and several abrupt changes in pressure after periods of rapid pumping, illustrating the extent of hydrogeologic "connection" between holes separated by $\sim 2.4 \mathrm{~km}$. This result is promising for planned crosshole experiments during future drilling and nondrilling expeditions. As with other such "uncontrolled" crosshole pressure signals, this one cannot be interpreted quantitatively because Holes U1301A and U1301B were not sealed during pumping. In fact, much of the fluid pumped probably came out of the holes at the seafloor and never entered the formation. We will monitor fluid flow volumes and rates during crosshole experiments completed during and after the next drilling expedition, allowing quantitative interpretation of pressure response at a large scale, in addition to monitoring fluid temperature, chemistry, and microbiology in multiple locations.

\section{Prospects for future experiments}

The beginning of IODP marks a new phase in scientific exploration and discovery below the seafloor, including use of sophisticated long-term monitoring systems. Expedition 301 deployed three CORK systems, two in new basement holes and one in an existing hole. The new CORKs share features with older systems but also introduce several novel approaches and technologies for improving resolution (temporal and spatial) of subseafloor monitoring and sampling. The new CORKs are currently monitoring pressure and temperature, collecting fluid samples, and injecting tracers and providing growth surfaces for microbiological ecosystems within distinct depth intervals in the upper oceanic crust. These systems will be visited periodically for data and sample retrieval using submersibles and ROVs and will have an $\sim 5$ y life span before downhole instrumentation will be recovered. Although these systems are providing useful information on their own, they are part of a crustalscale network of borehole observatories that will be used during future drilling and nondrilling expeditions to conduct multidisciplinary crosshole experiments. Planning is now under way to return to the Expedition 301 field area with a drilling vessel, hopefully in 2007 or 2008, to install additional observatory systems and initiate the crosshole work. Proponents are also exploring options for making several modifications to CORK and instrument string design and deployment strategies before the next drilling expedition to improve ease of handling and reliability.

\section{Acknowledgments}

Given the limited time available between scheduling and the start of Expedition 301 ( 9 months), the design, construction, and deployment of CORK systems could not have been accomplished without the extraordinary efforts of many individuals. We are grateful for the dedication, skill, and ingenuity of numerous Transocean personnel while at sea, including Core Technicans Joe (Bubba) Attryde and Phil Christie, Operations Manager Wayne Malone, Tool Pusher Jose (Pepe) Estevez, and Drillers Nick Parrish and Charlie Watts. We also thank the shipboard technicians and the rest of the Expedition 301 science party for their assistance and patience. Two equipment/supply deliveries by helicopter during Expedition 301 were essential for completing the CORK installations; we thank the staff of the U.S. Implementing Organization for arranging these and for all of their support for Expedition 301. John Ben- 
nest, Dave Miles, Jonathan Schmidt, and Ken Beverley devoted many extra hours to make the pressure logging system come together under a very tight schedule, and Keith Shepherd and the pilots of ROV ROPOS and Captain Adam Parsons and the officers and crew of the Thomas G. Thompson provided the vehicles and expert help with handling postdrilling installations and OsmoSampler recovery. Josh Plant helped to build the OsmoSampler systems. William Rugh, Radu Popa, Stefan Sievert, and Michael StorrieLombardi helped to build microbiological flow cells. These experiments were supported by the U.S. Science Support Program for IODP; U.S. National Science Foundation grants OCE0400462 (CGW), OCE0400102 (HJ), OCE0400471 (KB), and OCE0241791 (KJE and WB); the NASA Exobiology program (MF) NSF projects OCE9618243 and BES97-14286; and NASA project NNA04CC08A (JC).

\section{References}

Cowen, J.P., Giovannoni, S.J., Kenig, F., Johnson, H.P., Butterfield, D., Rappé, M.S., Hutnak, M., and Lam, P., 2003. Fluids from aging ocean crust that support microbial life. Science, 299:120-123. doi:10.1126/ science. 1075653

Davis, E.E., and Becker, K., 2002. Observations of naturalstate fluid pressures and temperatures in young oceanic crust and inferences regarding hydrothermal circulation. Earth. Planet. Sci. Lett., 204:231-248. doi:10.1016/ S0012-821X(02)00982-2

Davis, E.E., Becker, K., Pettigrew, T., Carson, B., and MacDonald, R., 1992. CORK: a hydrologic seal and downhole observatory for deep-ocean boreholes. In Davis, E.E., Mottl, M.J., Fisher, A.T., et al., Proc. ODP, Init. Repts., 139: College Station, TX (Ocean Drilling Program), 43-53.

Fisher, A.T., Becker, K., and Davis, E.E., 1997. The permeability of young oceanic crust east of Juan de Fuca Ridge determined using borehole thermal measurements. Geophys. Res. Lett., 24(11):1311-1314. doi:10.1029/ 97GL01286

Fisk, M.R., Giovannoni, S.J., and Thorseth, I.H., 1998. Alteration of oceanic volcanic glass: textural evidence of microbial activity. Science, 281:978-980. doi:10.1126/ science.281.5379.978

Fisk, M.R., Thorseth, I.H., Urbach, E., and Giovannoni, S.J., 2000. Investigation of microorganisms and DNA from subsurface thermal water and rock from the east flank of Juan de Fuca Ridge. In Fisher, A., Davis, E.E., and Escutia, C. (Eds.), Proc. ODP, Sci. Results, 168: College Station, TX (Ocean Drilling Program), 167-174.

Furnes, H., and Staudigel, H., 1999. Biological mediation in ocean crust alteration: how deep is the deep biosphere? Earth Planet. Sci. Lett., 166:97-103. doi:10.1016/S0012-821X(99)00005-9
International Working Group, 2001. Earth, Oceans and Life: Scientific Investigation of the Earth System Using Multiple Drilling Platforms and New Technologies. Integrated Ocean Drilling Program Initial Science Plan, 2003-2013. Washington (International Working Group Support Office).

Jannasch, H., Davis, E., Kastner, M., Morris, J., Pettigrew, T., Plant, J.N., Solomon, E., Villinger, H., and Wheat, C.G., 2003. CORK-II: long-term monitoring of fluid chemistry, fluxes, and hydrology in instrumented boreholes at the Costa Rica subduction zone. In Morris, J.D., Villinger, H.W., Klaus, A., Proc. ODP, Init. Repts., 205, 136 [CD-ROM]. Available from: Ocean Drilling Program, Texas A\&M University, College Station TX 77845-9547, USA.

Jannasch, H.W., Wheat, C.G., Plant, J., Kastner, M., and Stakes, D., 2004. Continuous chemical monitoring with osmotically pumped water samplers: OsmoSampler design and applications, Limnol. Oceanogr., 2:102-113.

Pfender, M., and Villinger, H., 2002. Miniaturized data loggers for deep sea sediment temperature gradient measurements. Mar. Geol., 186:557-570. doi:10.1016/ S0025-3227(02)00213-X

Shipboard Scientific Party, 1997. Rough basement transect (Sites 1026 and 1027). In Davis, E.E., Fisher, A.T., Firth, J.V., et al., Proc. ODP, Init. Repts., 168: College Station, TX (Ocean Drilling Program), 101-160.

Spinelli, G., Fisher, A.T., Wheat, C.G., Tryon, M.D., Brown, K.M., and Flegal, A.R., 2002, Groundwater seepage into northern San Francisco Bay: implications for dissolved metals budgets. Water Resour. Res., 38(7). doi:10.1029/ 2001WR000827

Staudigel, H., Yayanos, A., Chastain, R., Davies, G., Verdurmen, E.A.T., Schiffman, P., Bourcier, R., and De Baar, H., 1998. Biologically mediated dissolution of volcanic glass in seawater. Earth Planet. Sci. Lett., 164:233-244. doi:10.1016/S0012-821X(98)00207-6

Theeuwes F., and Yum, S.I., 1976. Principles of the design and operation of generic osmotic pumps for the delivery of semisolid or liquid drug formulations. Ann. Biomed. Eng., 4:343-353.

Thorseth, I.H., Torsvik, T., Furnes, H., and Muehlenbachs, K., 1995. Microbes play an important role in the alteration of oceanic crust. Chem. Geol., 126:137-146. doi:10.1016/0009-2541(95)00114-8

Wheat, C.G., Jannasch, H.W., Kastner, M., Plant, J.N., and DeCarlo, E.H., 2003. Seawater transport and reaction in upper oceanic basaltic basement: chemical data from continuous monitoring of sealed boreholes in a ridge flank environment. Earth Planet. Sci. Lett., 216:549-564. doi:10.1016/S0012-821X(03)00549-1

Wheat, C.G., Jannasch, H.W., Kastner, M., Plant, J.N., DeCarlo, E.H., and Lebon, G., 2004. Venting formation fluids from deep-sea boreholes in a ridge flank setting: ODP Sites 1025 and 1026. Geochem., Geophys., Geosyst., 5(8). doi:10.1029/2004GC000710 
Wheat, C.G., Jannasch, H.W., Plant, J.N., Moyer, C.L., Sansone, F.J., and McMurtry, G.M., 2000. Continuous sampling of hydrothermal fluids from Loihi Seamount after the 1996 event. J. Geophys. Res., 105(8):19353-19367.

Publication: 31 October 2005

MS 301-103 
Figure F1. Schematic of casing and CORK systems deployed during Expedition 301, idealized and not to scale. The system shown uses four nested casing strings, like CORKs in Holes U1301A and U1301B, and isolates a single zone of uppermost basement, like CORKs in Holes 1026B and U1301A. All of the CORK systems deployed during Expedition 301 are sealed in the throat of the reentry cone within 103/4 inch casing. The primary CORK casing is $4 \frac{1}{2}$ inches in diameter and is sealed with two plugs, one at depth and one at the top of the CORK head. Additional seals are provided by cement at the base of the 16 and $10^{3} / 4$ inch casing strings; see discussion in text regarding CORK design and sealing operations. Expedition 301 CORKs contain up to nine fluid, microbiological, and pressure sampling lines, with ports and screens at various depths, and a variety of fluid and microbiological sampling systems suspended on Spectra cable at depth. Temperatures are recorded with autonomous sensor and logging instruments incorporated into the fluid and microbiological samplers or hung independently from the Spectra cable. Specific configurations for each Expedition 301 CORK are shown in later figures and tables and discussed in the text.

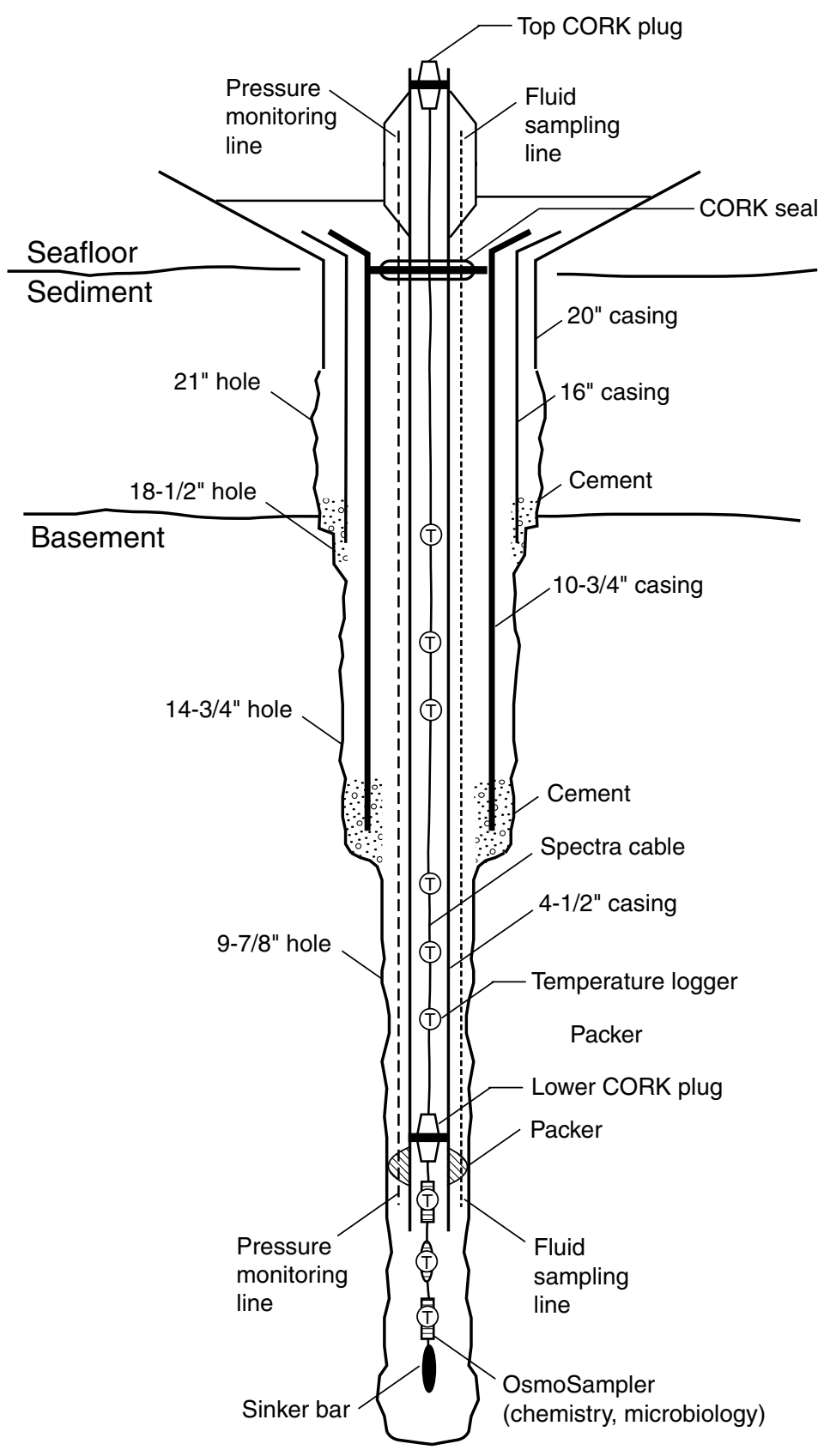


Figure F2. Expedition 301 CORK bodies. A. Four CORK bodies secured to the top of the Core Tech shop, behind the rig floor, near the start of Expedition 301. The tops of the CORK bodies are at the bottom of the photograph, and first short sections of $4 \frac{1}{2}$ inch casing are visible at the top of the photograph, extending beyond the roof of the core tech shop, just below the CORK seals. The vertical cylinders on the left side of the image are casing hangers and casing deployment tools of various diameters. B. CORK being hoisted to the rig floor for deployment in Hole U1301B. The hole at the top of the CORK body will receive the instrument string and plugs. Visible on the right side of the CORK body is one of three instrument and access bays, each occupying $120^{\circ}$ of arc and $1.5 \mathrm{~m}$ long. The bay visible in this photograph is for monitoring fluid pressure. Valves at the top of the bay (right side when CORK deployed vertically) control access and venting of the pressure monitoring lines, and the plate with holes at the bottom of the bay (left side when CORK deployed vertically) was designed to hold a pressure gauge and logging system.
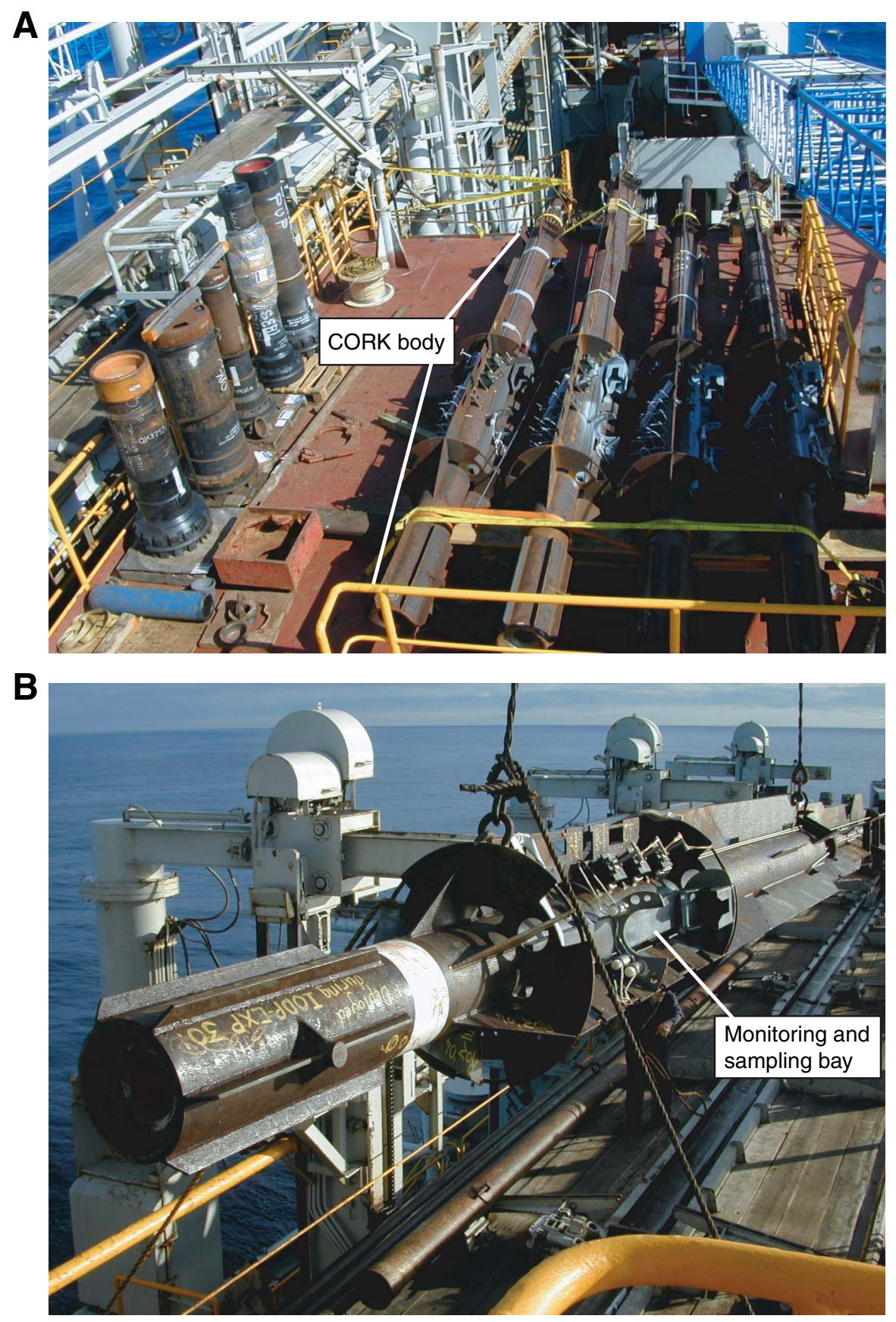
Figure F3. CORK seals and umbilical tubing. A. IODP operations, engineering, and technical personnel attach umbilical tubing to connectors that pass through the CORK seal. The tubing above the CORK seal extends up to the sample and monitoring bays in the CORK head (Fig. F2). B. Completed connections between umbilical and tubing above the CORK seal are checked prior to deployment.
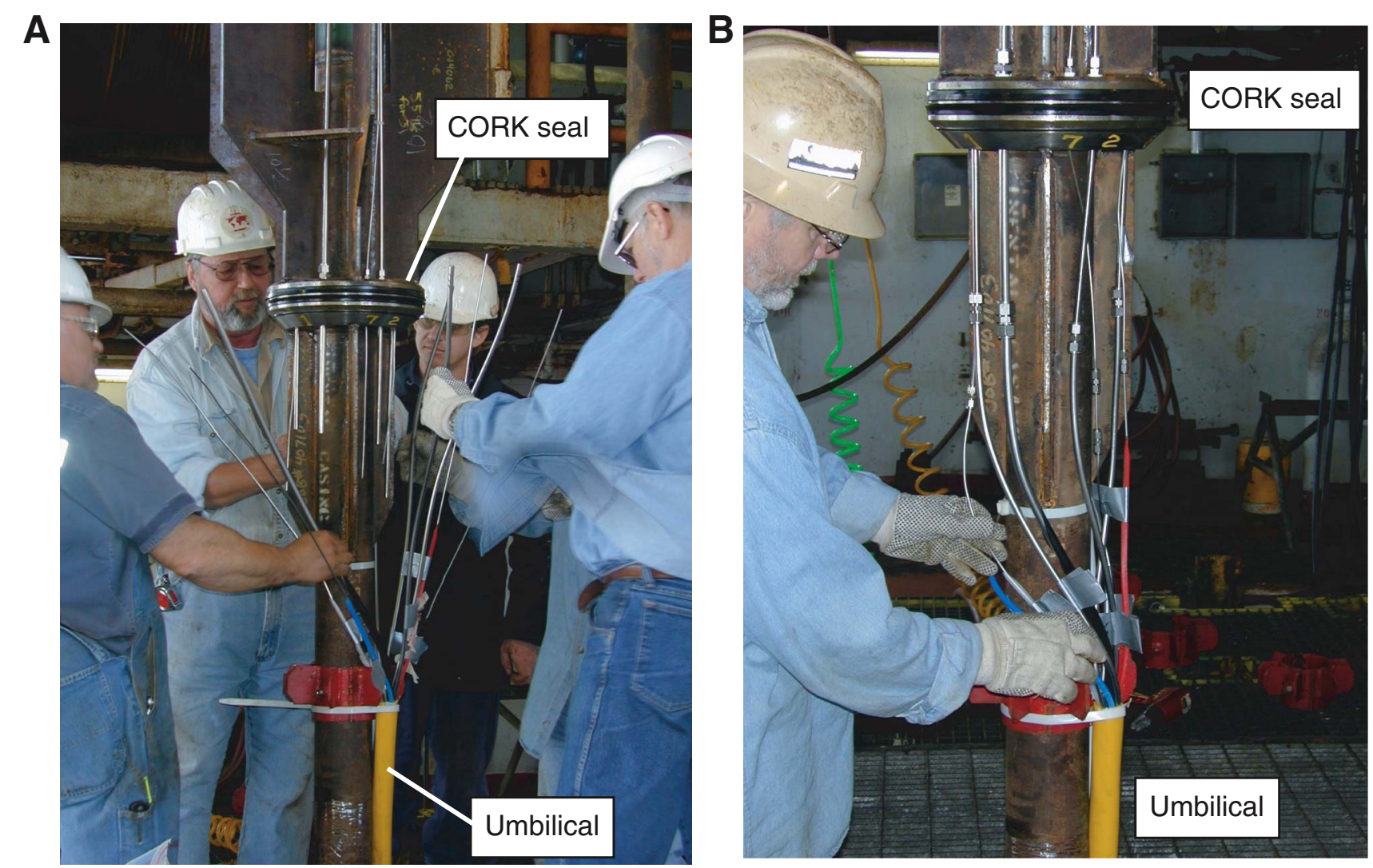
Figure F4. CORK umbilical tubing samples from Expedition 301. Pen for scale. The Hole 1026B umbilical comprised surplus material from Leg 205. The Hole U1301A umbilical comprised surplus material from Leg 196. The Hole U1301B umbilical (and that intended for use in Hole 1027C) were created for Expedition 301. The main tubing bundle (yellow) contains packer inflation, pressure monitoring, and fluid sampling lines. All of these umbilicals are made of stainless steel encased in a plastic housing. The separate tube (gray) contains a more chemically inert Tefzel line, surrounded by a metal braid and covered with plastic, used for microbiological sampling in the lower interval in Hole U1301B.

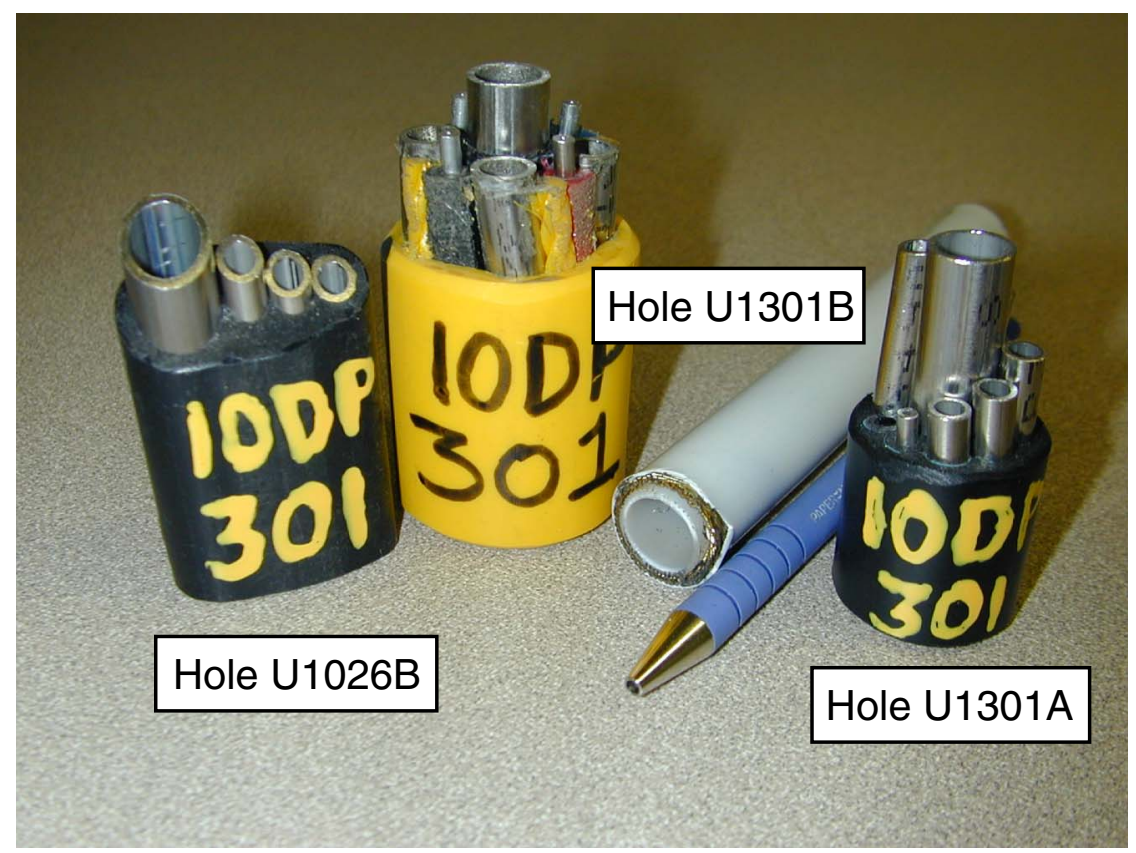


Figure F5. Examples of calibration data and fit residuals from the two kinds of autonomous temperature loggers deployed in CORK observatories during Expedition 301. In each case, symbols for factory calibration indicate temperatures indicated by the tools. We crossplotted tool and bath temperatures and fit second- and third-order polynomials to the data, yielding the residual misfits shown. Fitting with polynomials significantly improves tool accuracy and helps to eliminate systematic misfit. A. Calibration results from Onset tool 598. B. Calibration results from Antares tool 003.
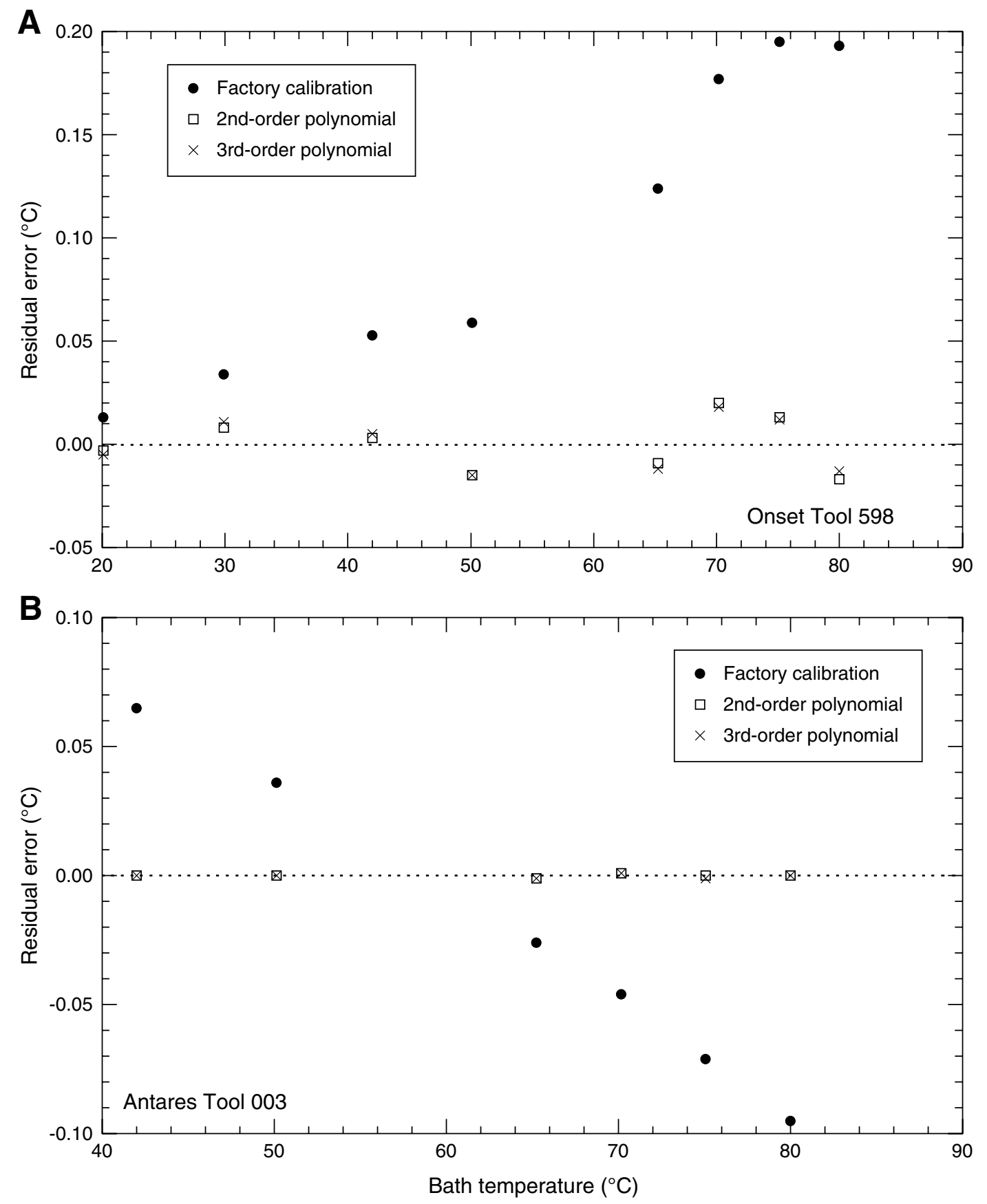
Figure F6. Autonomous temperature loggers deployed on CORK strings during Expedition 301. A. Onset logger deployed inside OsmoSampler housing. Logger is sheathed inside rubber weave and attached to central strength member with cable ties, between two OsmoSampler units, and later surrounded with a perforated high-density polyethylene (HDPE) sleeve. B. Antares logger deployed inside microbiological growth system. Logger is sheathed inside rubber weave and attached to central strength member with cable ties, between an osmotic pump and an growth housing, and later surrounded with a perforated HDPE sleeve. C. Autonomous temperature loggers attached to Spectra line. Both kinds of loggers are sheathed inside rubber weave and attached to line with cable ties. Loggers are protected during deployment by perforated industrial hose.

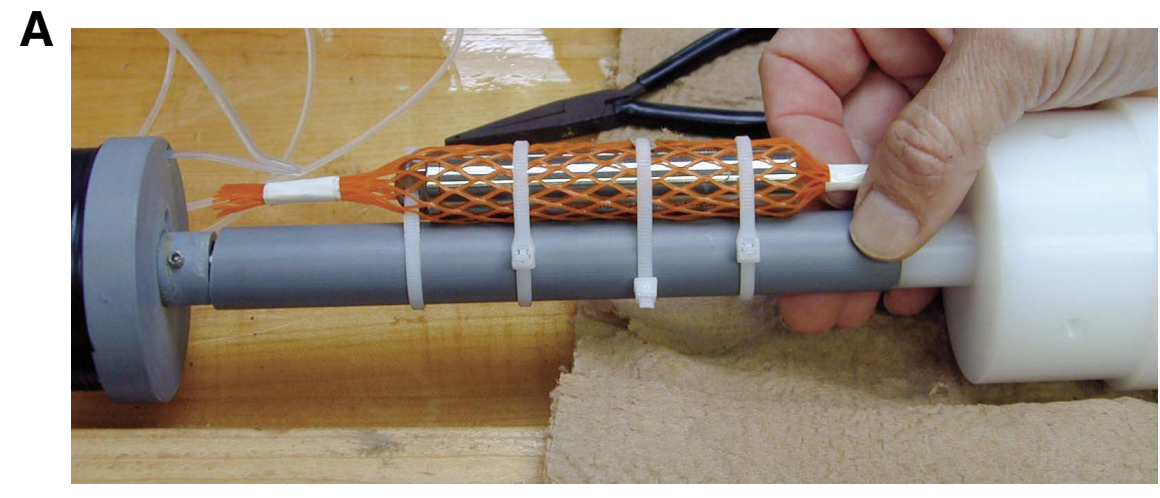

B

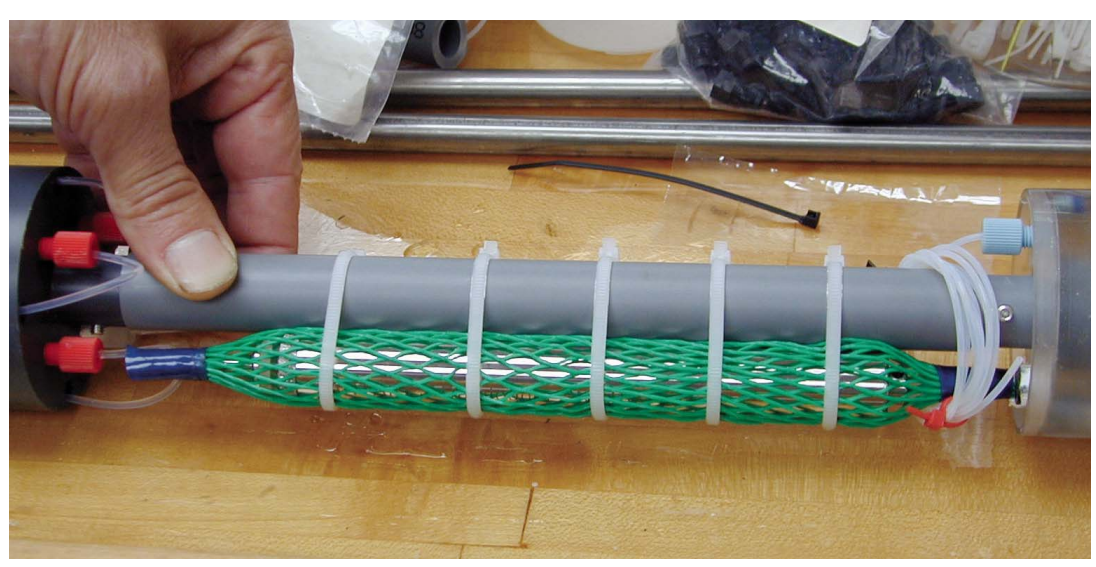

C

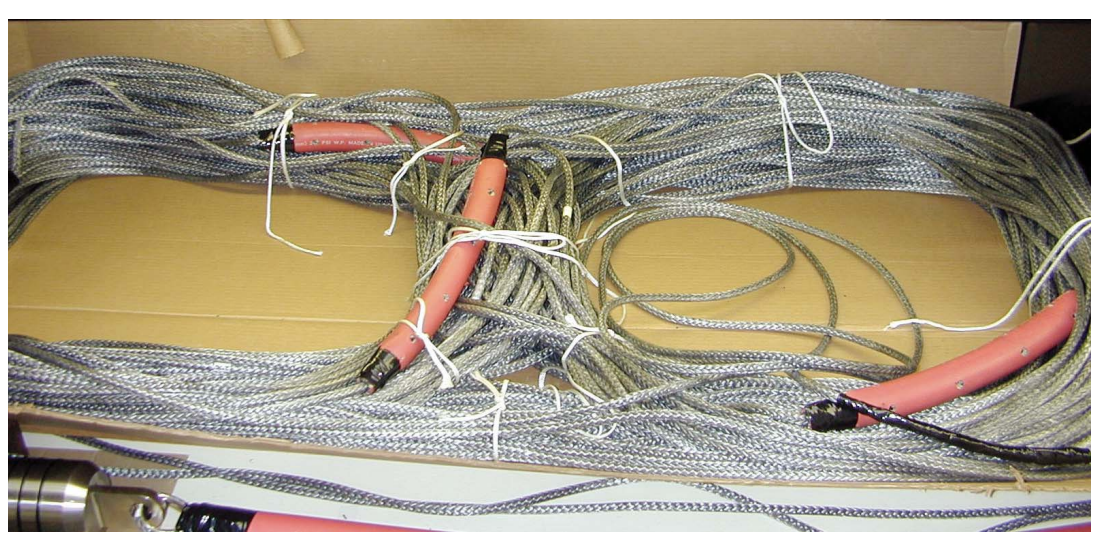


Figure F7. Schematic of downhole OsmoSampler system. A. Outside view. B. Cross section view. C. Pump detail. System consists of (1) a $1 / 2$ inch diameter stainless steel strength member up to $4 \mathrm{~m}$ long connected to (2) two shackle eyes and (3) a protective high-density polyethylene (HDPE) protective sleeve. The (4) osmotic pump pulls water through (4a) small-diameter tubing attached to an intake by the diffusion of water from the (4b) freshwater chamber through the (4c) osmotic membrane to the (4d) saturated salt chamber. Brine is expelled out the (4e) outflow. Fluid samples are drawn into and stored within a series of sample spools, comprising up to several kilometers of small-diameter tubing. Equilibration holes in the (6) HDPE sleeve allow ambient fluid to circulate around the OsmoSampler components. Three to six downhole OsmoSampler systems were deployed below each Expedition 301 CORK.

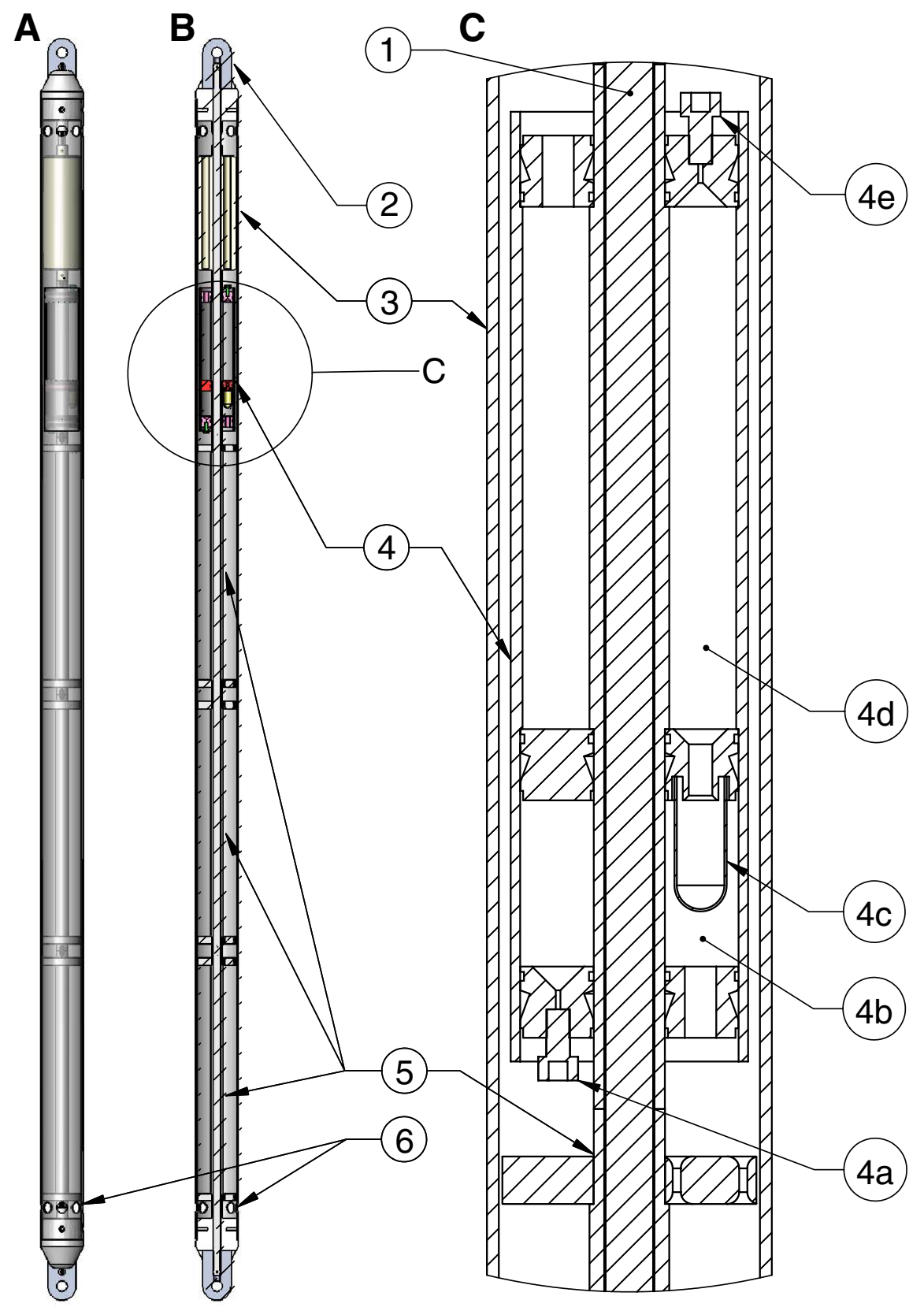


Figure F8. Calculations of expected tracer concentrations below the CORK in Hole U1301A. Tracer concentrations were estimated based on the size of the open interval, injectate concentration, rate of tracer injection, and formation fluid exchange rates of 17.5 to $1750 \mathrm{~kg} /$ day, as shown. These exchange rates were estimated based on results of earlier tracer dilution experiments in Holes 1024C and 1027C (Wheat et al., 2003). Three different tracers are being injected continuously at depth below CORKs in Holes 1026B, U1301A, and U1301B (Table T3). A. Calculated Cs concentration versus time, full scale. B. Calculated Cs concentration versus time, low scale. C. Calculated Tm concentration versus time, full scale. D. Calculated Tm concentration versus time, low scale. E. Calculated $\mathrm{Yb}$ concentration versus time, full scale. F. Calculated $\mathrm{Yb}$ concentration versus time, low scale.
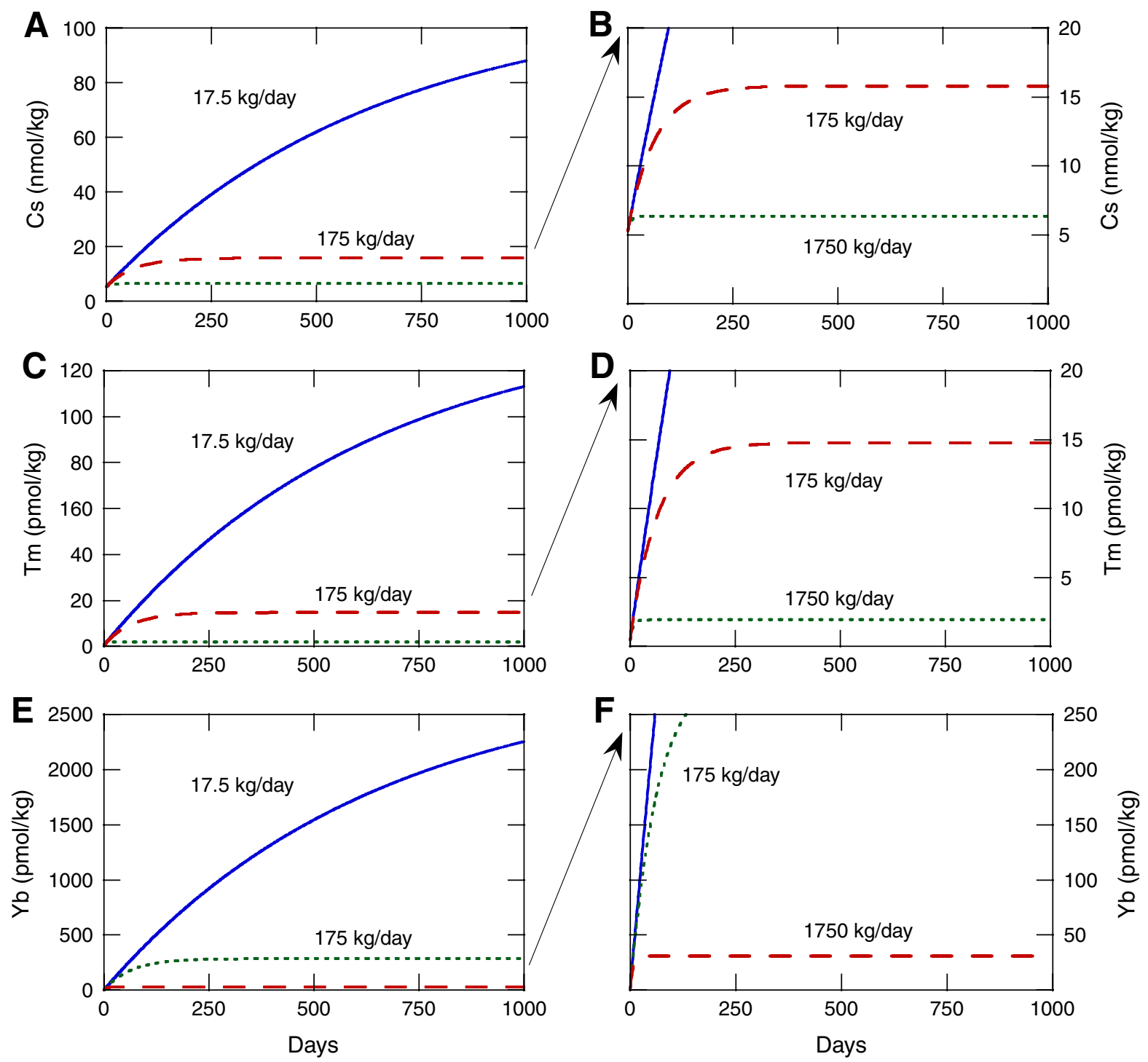
Figure F9. Up to three submersible/remotely operated vehicle-installable CORK head OsmoSamplers can be mounted on the rack contained within one of the bays on the head of each Expedition 301 CORK. The OsmoSamplers are mounted on steel plates containing valves and fittings. A. Shown from left to right are (1) a seafloor OsmoSampler being installed, (2) an installed and locked OsmoSampler, and (3) an empty rack. Each OsmoSampler plate is positioned with a bottom shoe and a top alignment track and locked into place with a rotating T-handle at the top of the plate (vertical = unlocked; horizontal = locked). There are two valves for each OsmoSampler mounted on the CORK head, below the sampler plates, and two additional (optional) valves on each OsmoSampler are used to control sample and pressure-compensation lines. These valves rotate $90^{\circ}$, where vertical $=\mathrm{CCW}=$ open and horizontal $=\mathrm{CW}=$ closed. $\mathbf{B}$. Detail of OsmoSampler nipple assembly mounted in CORK head, allowing connection to sample tubing extending to isolated intervals at depth. Nipples are machined from titanium and mounted in a high-density polyethylene (HDPE) block. C. Dimensions for nipple assemblies. Each removable OsmoSampler incorporates two mating female polyetheretherketone (PEEK) connectors. D. Cross-section detail of nipple assembly showing (1) nipples mounted in (2) HDPE block, (3) PEEK connectors, and their (4) retaining rings held by (5) set screws and an alignment pin. The locations of the (6) permanent frame and the (7) OsmoSampler plate are shown as dashed lines. These are $1.27 \mathrm{~cm}$ apart when fully mounted.

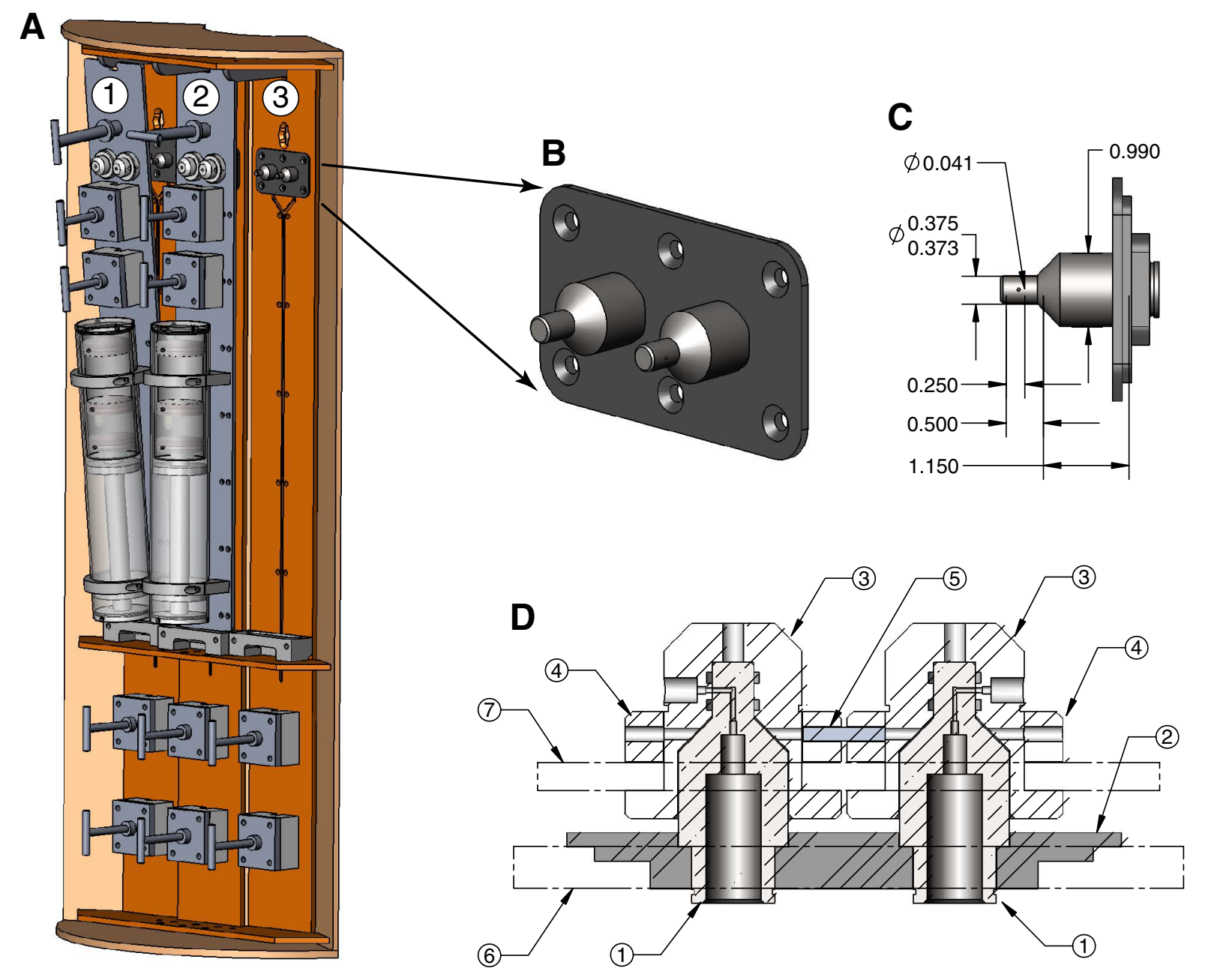


Figure F10. Examples of microbiological attachment, growth, and alteration experiments deployed below CORKs during Expedition 301. A. Passive experiment with polished rock and mineral chips fits inside the high-density polyethylene (HDPE) sleeve that holds OsmoSamplers. Water flows through perforations in the HDPE sleeve as a result of convection in the borehole, and polished surfaces offer opportunities for microbial attachment and growth. B. Flow cell experiments containing crushed mineral substrate. The OsmoSampler shown at the top of the image pumps crustal fluids through the two flow cells below it. The lower flow cell is a biotic experiment and the upper flow cell is an abiotic control. The two cells are connected by Teflon tubing and a $0.2 \mu \mathrm{m}$ filter. Flow cell components are attached to a $1 / 2$ inch steel rod that passes through the center of the units.
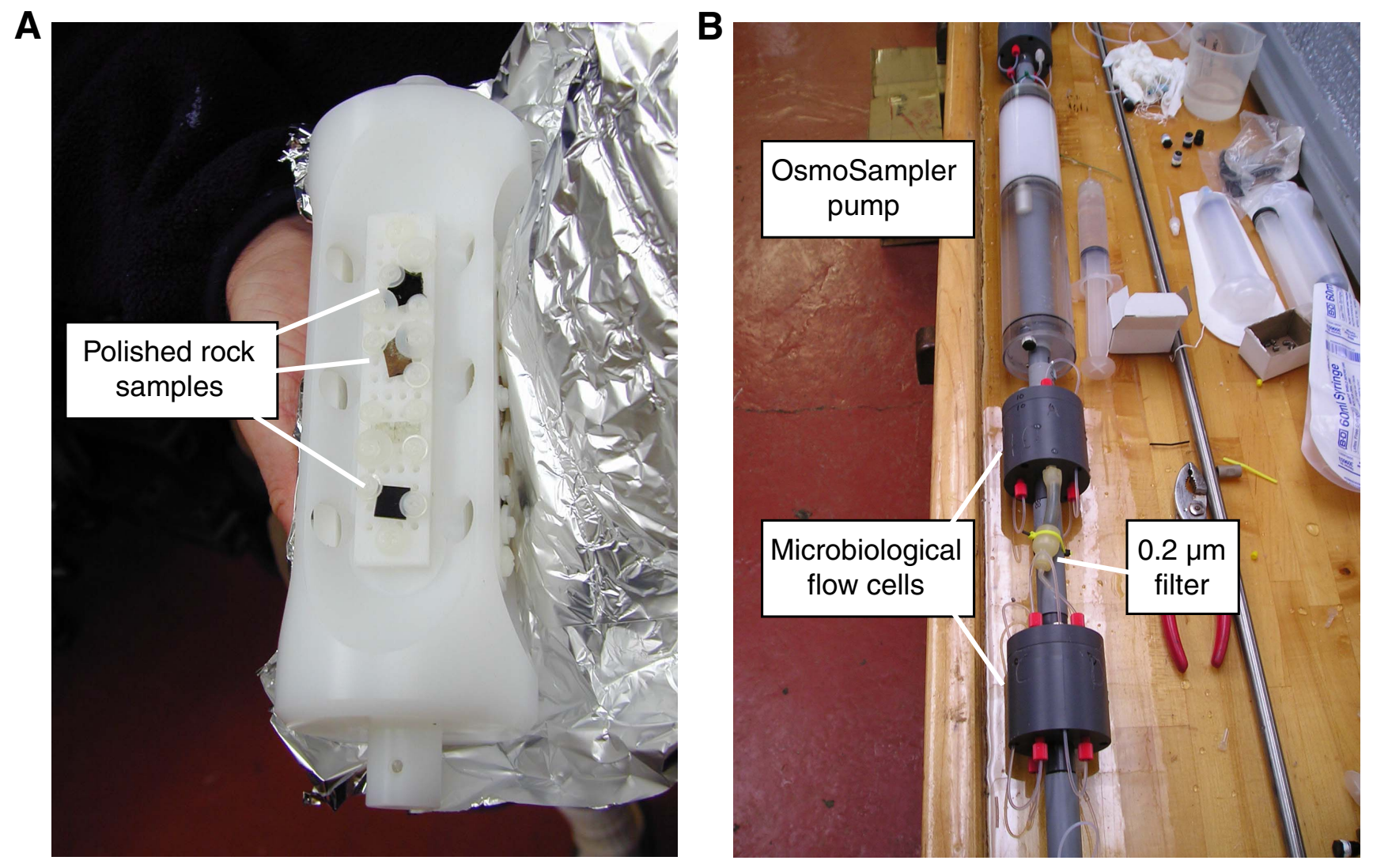
Figure F11. Engineering drawing of CORK system deployed in Hole 1026B during Expedition 301 (modified from the "Expedition 301 summary" chapter). ROV = remotely operated vehicle. MBR = mechanical bit release. TAM = TAM International.

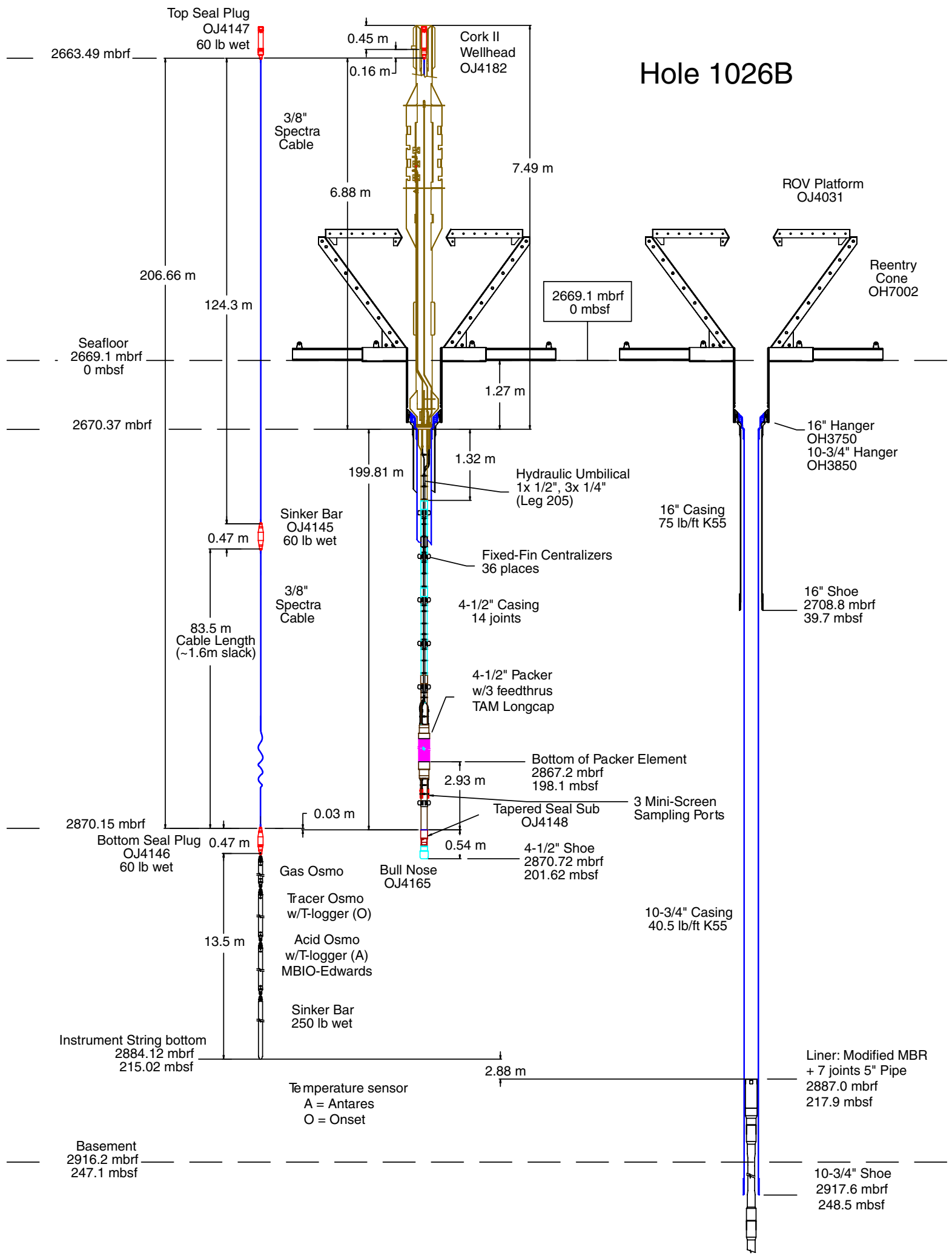


Figure F12. Plumbing schematic of CORK system deployed in Hole 1026B during Expedition 301. An OsmoSampler was attached during deployment to valve 6, as indicated, and subsequently recovered during ROV operations on 4 September 2004. This system contains redundant sampling opportunities of a single isolated zone through use of T-connectors. A pressure gauge can be attached to fitting B during future servicing visits to examine pressure conditions within the cased interval above the CORK packer. $\mathrm{OD}=$ outer diameter. $\mathrm{BW}=$ bottom water.

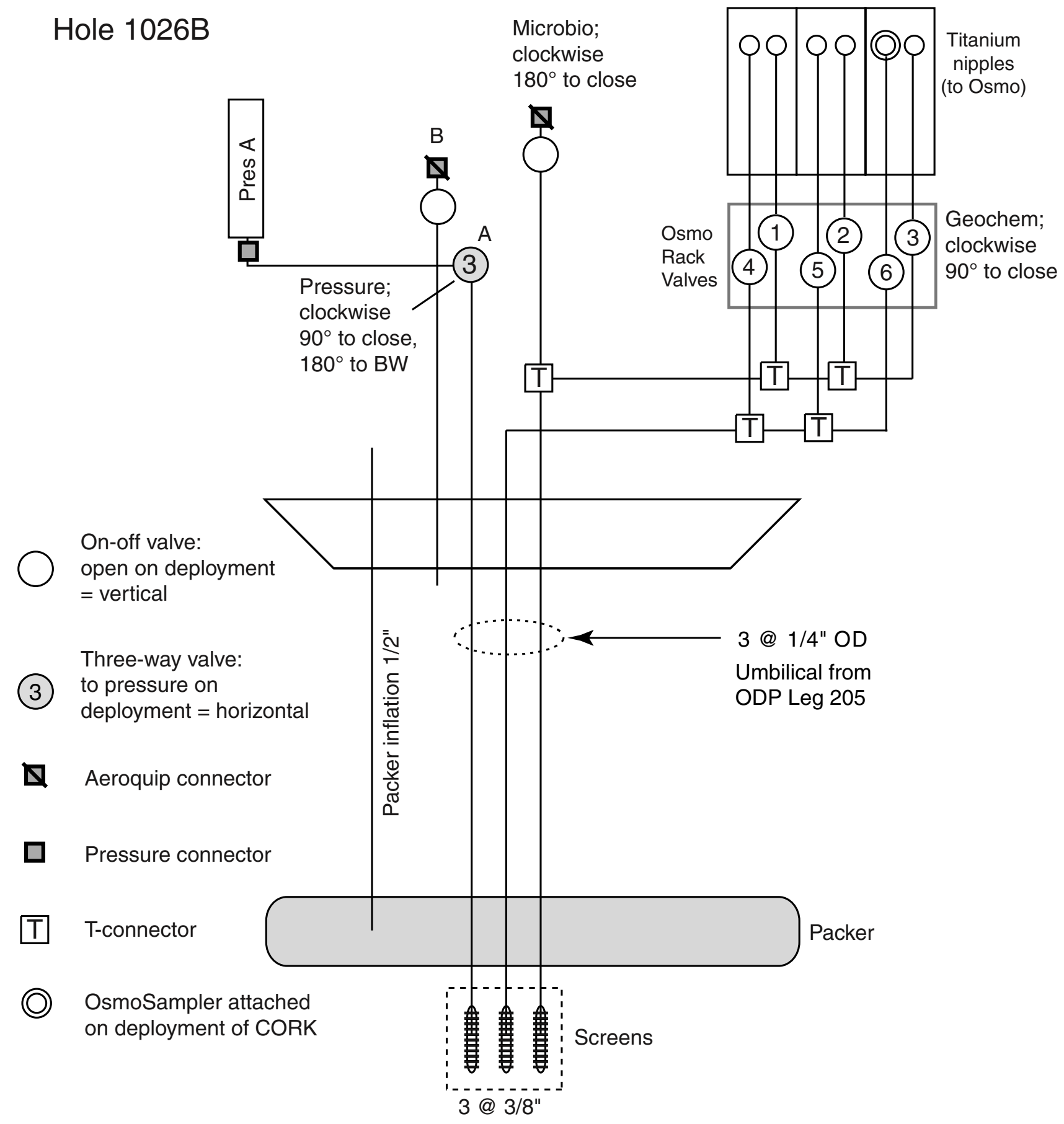


Figure F13. Photos of CORK head for system deployed in Hole 1026B. A. Microbiology and auxiliary sampling bay, showing packer inflation line and sampling valve (held open during deployment with rubber bands). B. Fluid sampling bay with one CORK head OsmoSampling system attached. All values are open for deployment. Pressure bay is not visible in these images, but it contains two pressure monitoring fittings and valves, one plumbed to the formation interval below the casing packer, and a second plumbed to the interval between the packer and the CORK seal at the CORK head.

A

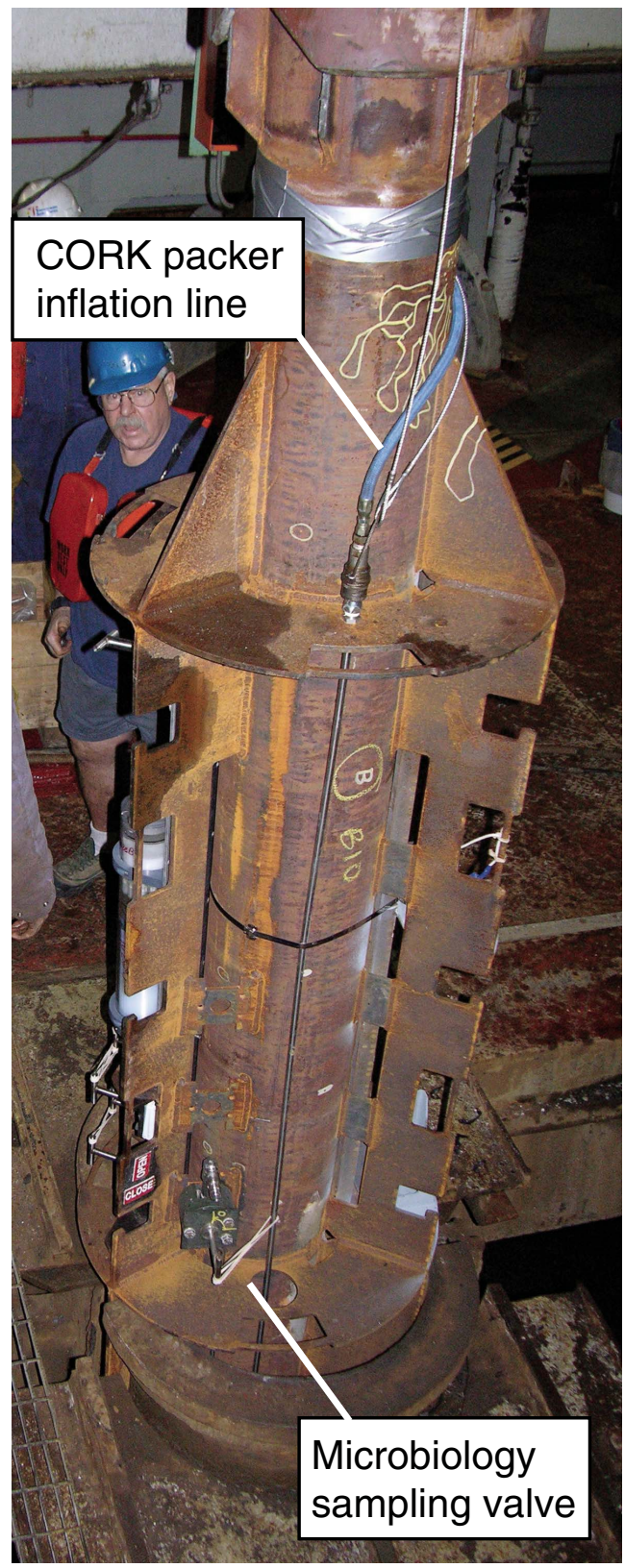

B

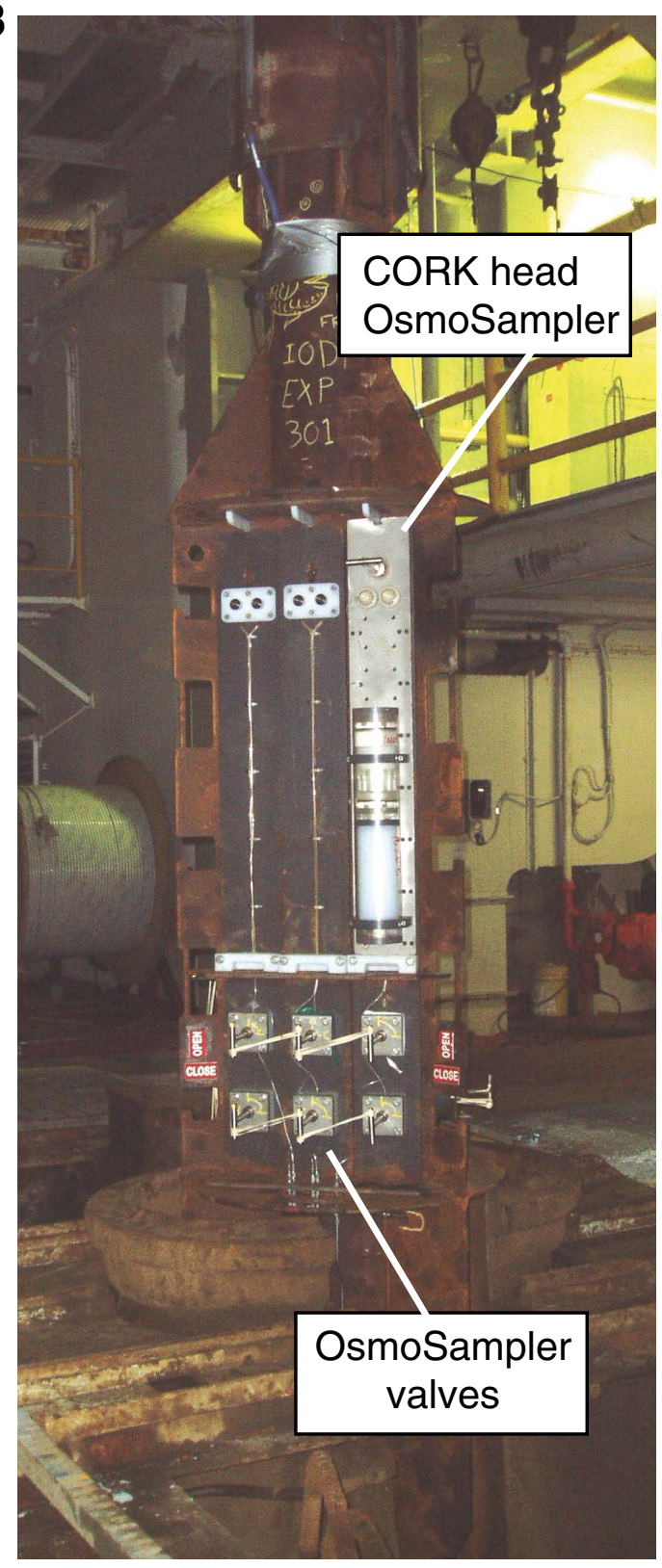


Figure F14. Engineering drawing of CORK system deployed in Hole U1301A during Expedition 301 (modified from the "Expedition 301 summary" chapter). ROV = remotely operated vehicle, TAM = TAM international. $\mathrm{OD}=$ outer diameter, ID = internal diameter.

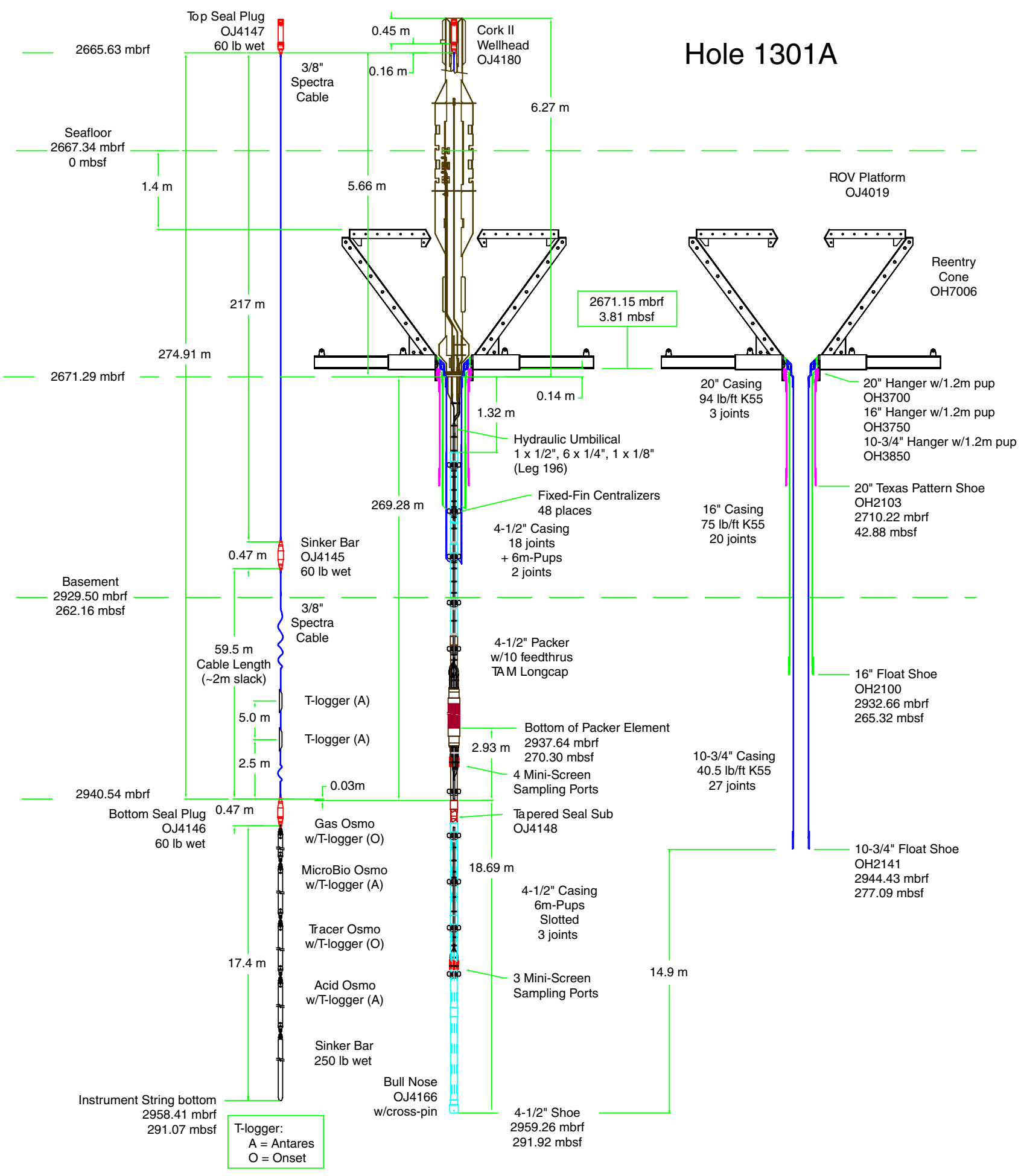


Figure F15. Plumbing schematic of CORK system deployed in Hole U1301A during Expedition 301. An OsmoSampler was attached during deployment to valve 6 , as indicated, and subsequently recovered during September 2004 ROV operations. This system contains redundant sampling opportunities of a single isolated zone through use of T-connectors. The pressure logging system monitors both the isolated basement zone below the casing packer and the zone within the cased interval about the packer, to evaluate system performance over time. $\mathrm{OD}=$ outer diameter, $\mathrm{ID}=$ internal diameter. $\mathrm{BW}=$ bottom water.

\section{Hole 1301A}

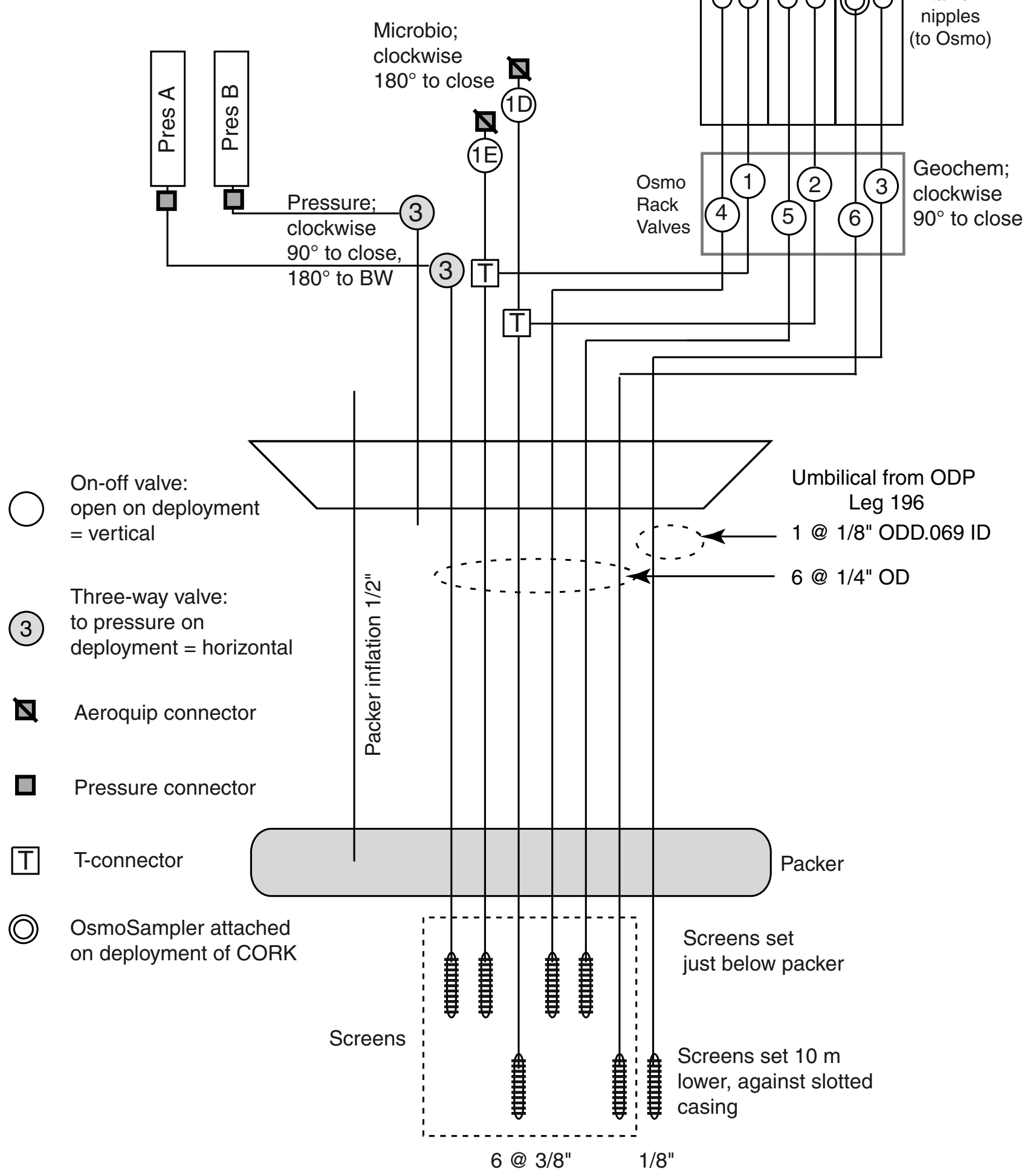


Figure F16. Photos of CORK head for system deployed in Hole U1301A. A. Pressure bay showing location of logger frame and valves used to control access to pressure lines. B. Microbiology and auxiliary sampling bay showing sampling valves held open during deployment with rubber bands attached to the packer inflation line. C. Fluid sampling bay with one CORK head OsmoSampler system attached. All values are open for deployment.
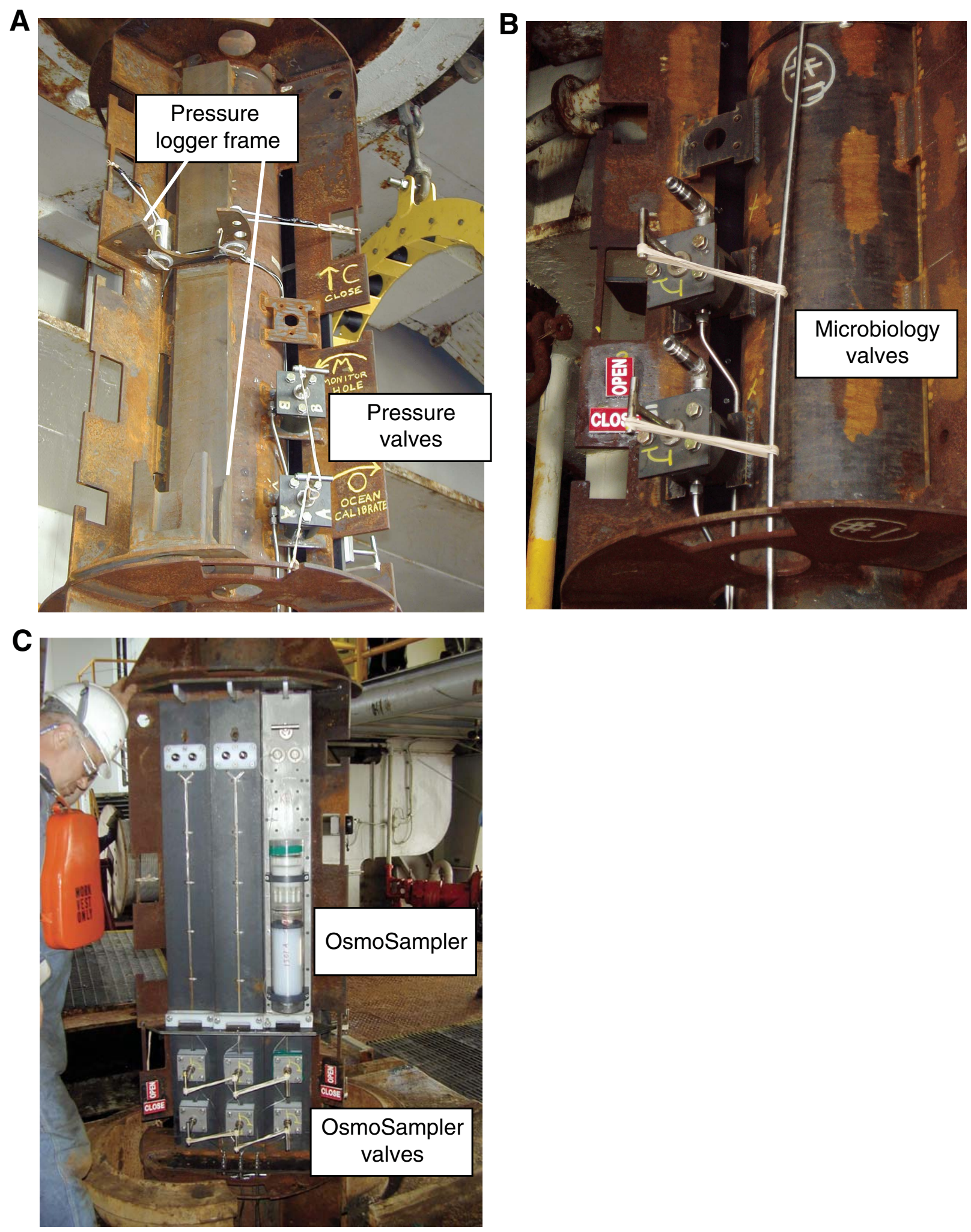
Figure F17. Engineering drawing of CORK system deployed in Hole U1301B during Expedition 301 (modified from the "Expedition 301 summary" chapter). ROV = remotely operated vehicle. TAM = TAM International.

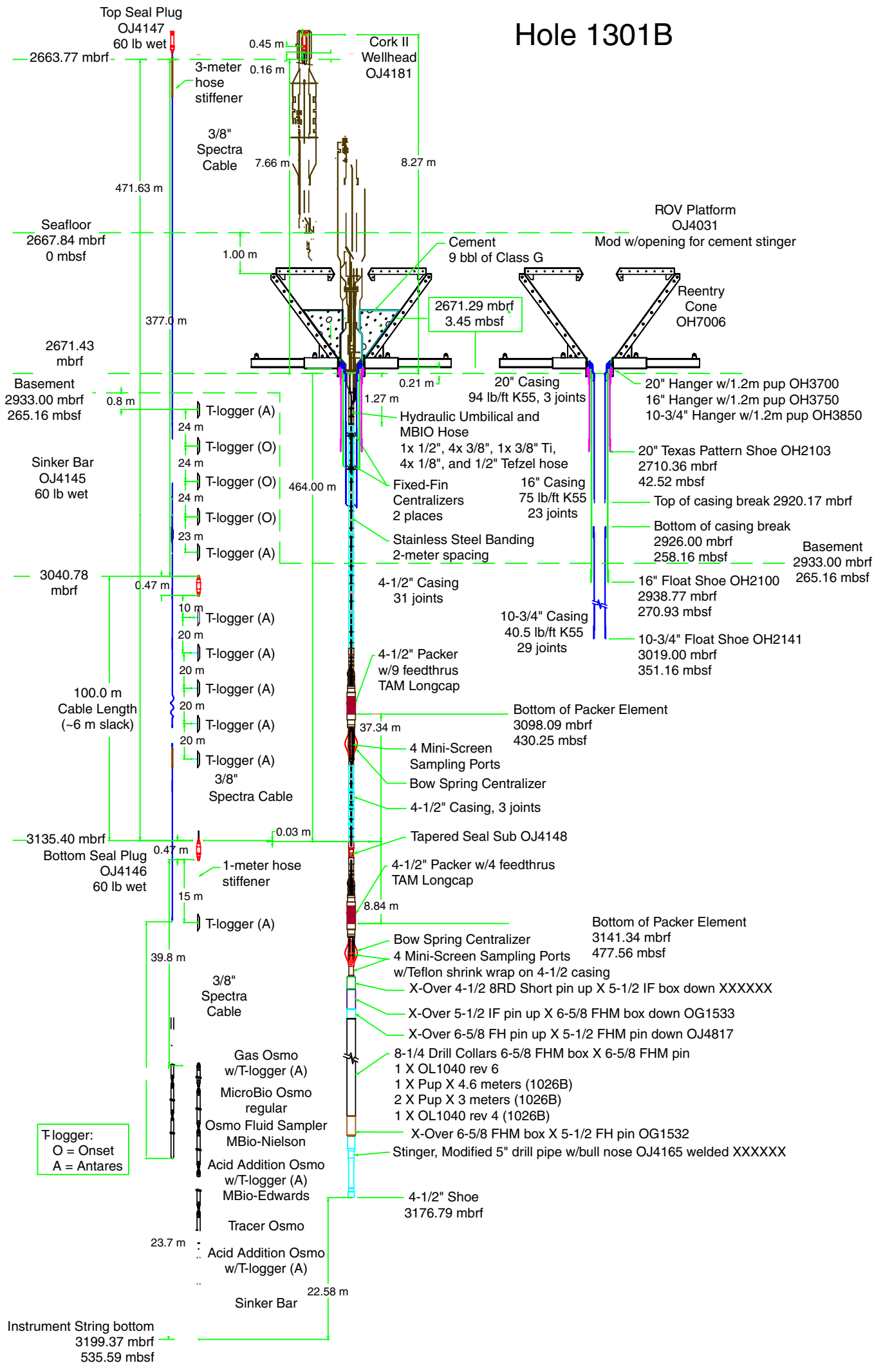


Figure F18. Plumbing schematic of CORK system deployed in Hole U1301B during Expedition 301. Three OsmoSamplers were attached during deployment to valves 1,2, and 6, as indicated; OsmoSamplers attached to valves 1 and 2 were subsequently recovered during September 2004 ROV operations, and the remaining system was left in place. This system contains redundant sampling opportunities of two isolated zones through use of T-connectors. The pressure logging system monitors three zones: one below the deepest casing packer, one between the two packers, and one between the shallowest packer and the seafloor, including uppermost basement and the annular volumes between the 16 and $4 \frac{1}{2} 2$ inch casing strings. BW = bottom water.

Hole 1301B

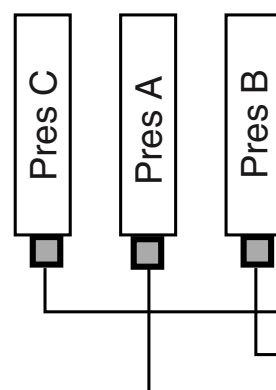

Microbio; clockwise $90^{\circ}$ to close

Pressure; clockwise $90^{\circ}$ to close, $180^{\circ}$ to BW

(3)

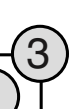

On-off valve: open on deployment
$=$ vertical

Three-way valve:

(3) to pressure on deployment $=$ horizontal

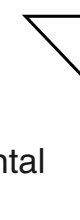

$\mathbf{Q}$ Aeroquip connector

Pressure connector

T T-connector

(O) OsmoSampler attached on deployment of CORK

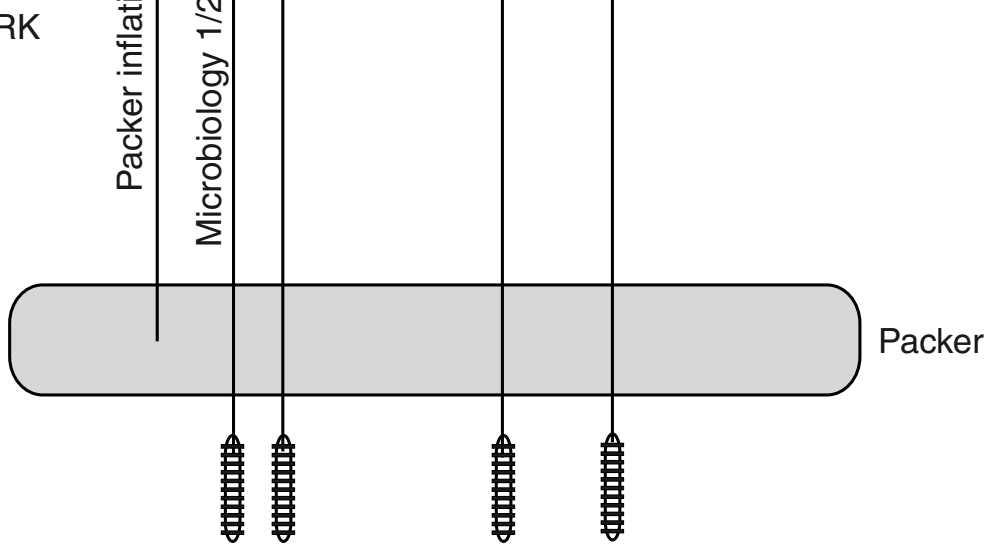


Figure F19. Photos of CORK head for system deployed in Hole U1301B. A. CORK body on deck prior to deployment, after modifications to extend the height of the CORK head. This was accomplished by welding a short piece of $4 \frac{1}{2}$ inch casing below the original CORK seal, attaching a new seal, and adding gussets along the extended section for stability. B. Pressure bay showing location of logger frame and valves used to control access to pressure lines. C. Fluid sampling bay with three CORK head OsmoSampling systems attached. All values are open for deployment. D. Microbiology and auxiliary sampling bay showing sampling valves held open during deployment with rubber bands attached to the packer inflation line.
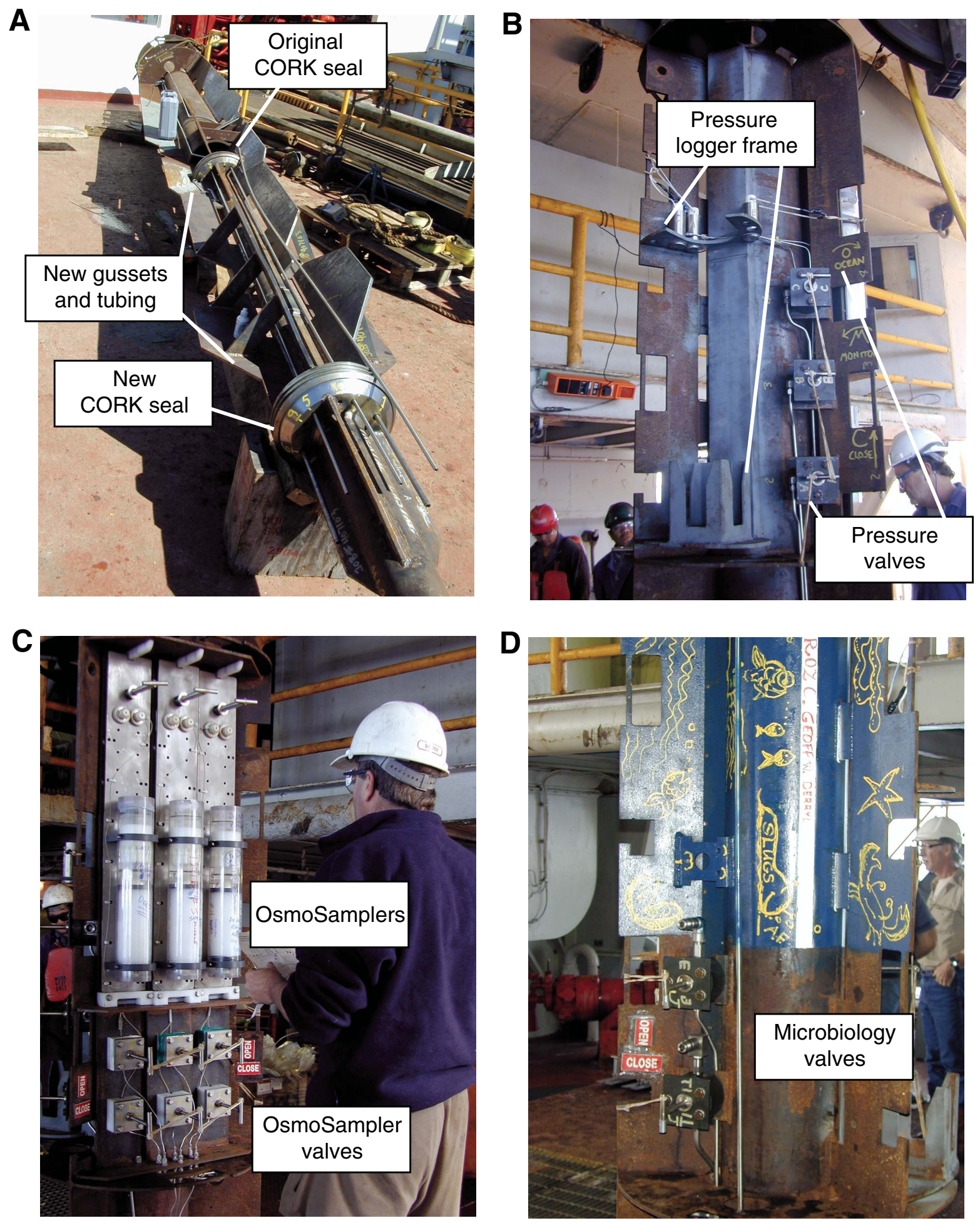
Figure F20. Photos of CORK pressure logging systems prior to deployment from the Thomas G. Thompson during September 2004. A. Pressure logging systems for CORKs at Holes 1026B and U1301A. The original design was intended to place the pressure loggers in frames on the CORK heads, but this design was subsequently modified to place the loggers on separate frames on the submersible/ROV platform in the cone or on the seafloor. Each logging system has a hydraulic coupler that mates to individual pressure lines in the CORK head. B. Elevator system used to deploy pressure logging systems on Expedition 301 observatories.
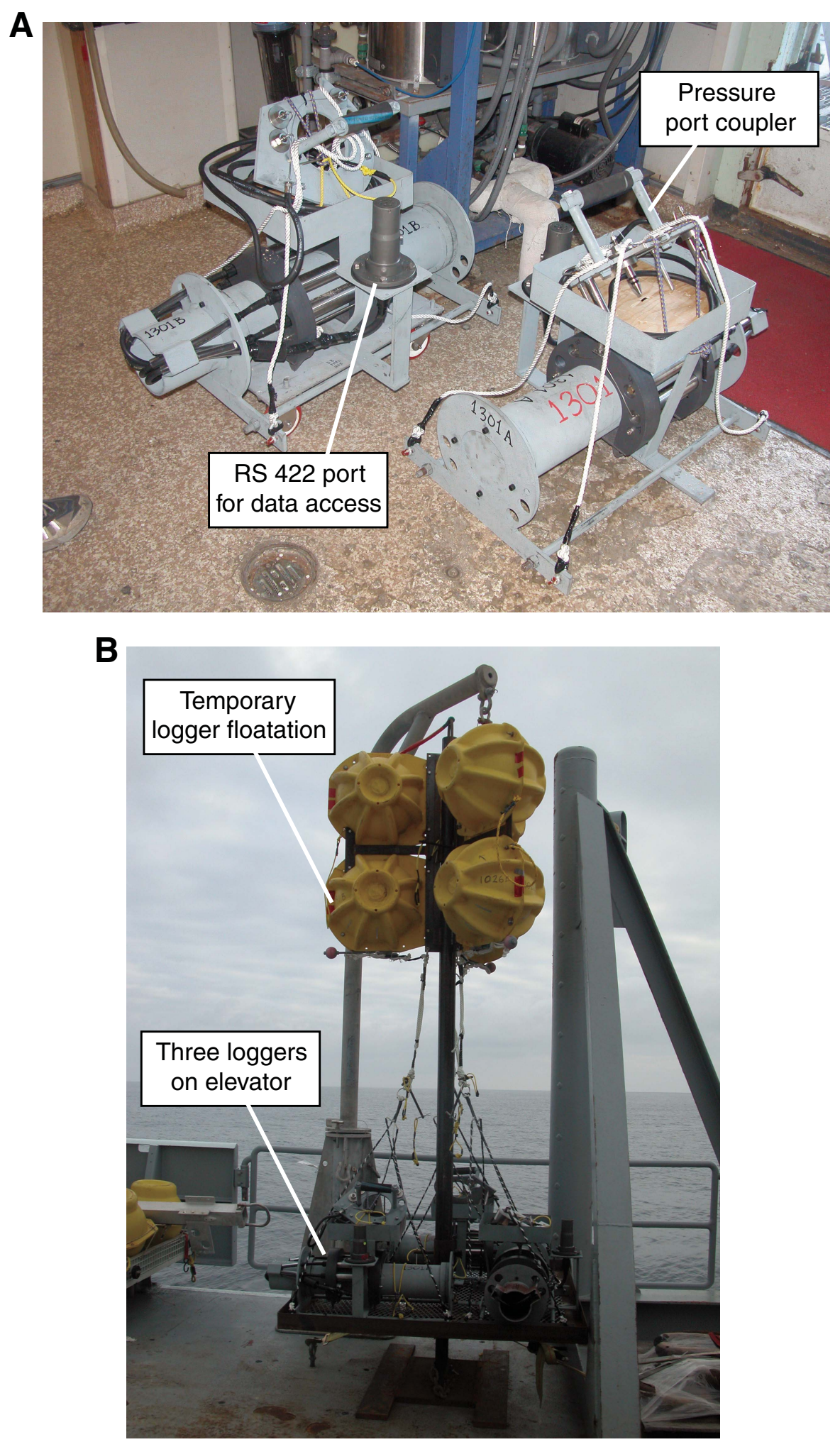
Figure F21. Preliminary pressure data collected in the Expedition 301 CORK deployed in Hole 1026B and the previously existing CORK in Hole 1027C. Hole 1026B data were recorded using the new pressure monitoring systems (Fig. F20) deployed in September 2004. A. Pressure record during time when instruments were carried from the elevator to the CORK in Hole 1026B and connections were made to the valves on the CORK head. B. Detail of pressure record showing general quality of the data. C. Detail of end of initial record, indicating the presence of excess pressure (relative to hydrostatic) in Hole 1026B. As described in the text, this excess pressure comprises a combination of natural overpressure and additional thermal buoyancy in the borehole induced during seepage before the valves were closed. D. Evidence that the upper oceanic crust is hydrogeologically "connected" from Site U1301 to Site 1027, $2.4 \mathrm{~km}$ away. Rig pumping records from Site U1301 and pressure data downloaded from the CORK system in Hole 1027C. Pressure record has been corrected for tidal loading. There is a clear correlation between pumping in basement in Holes U1301A and U1301B and the pressure response in Hole 1027C. Several particularly abrupt "events" are marked with red arrows. $\mathrm{ROV}=$ remotely operated vehicle. JD = Julian day.

A
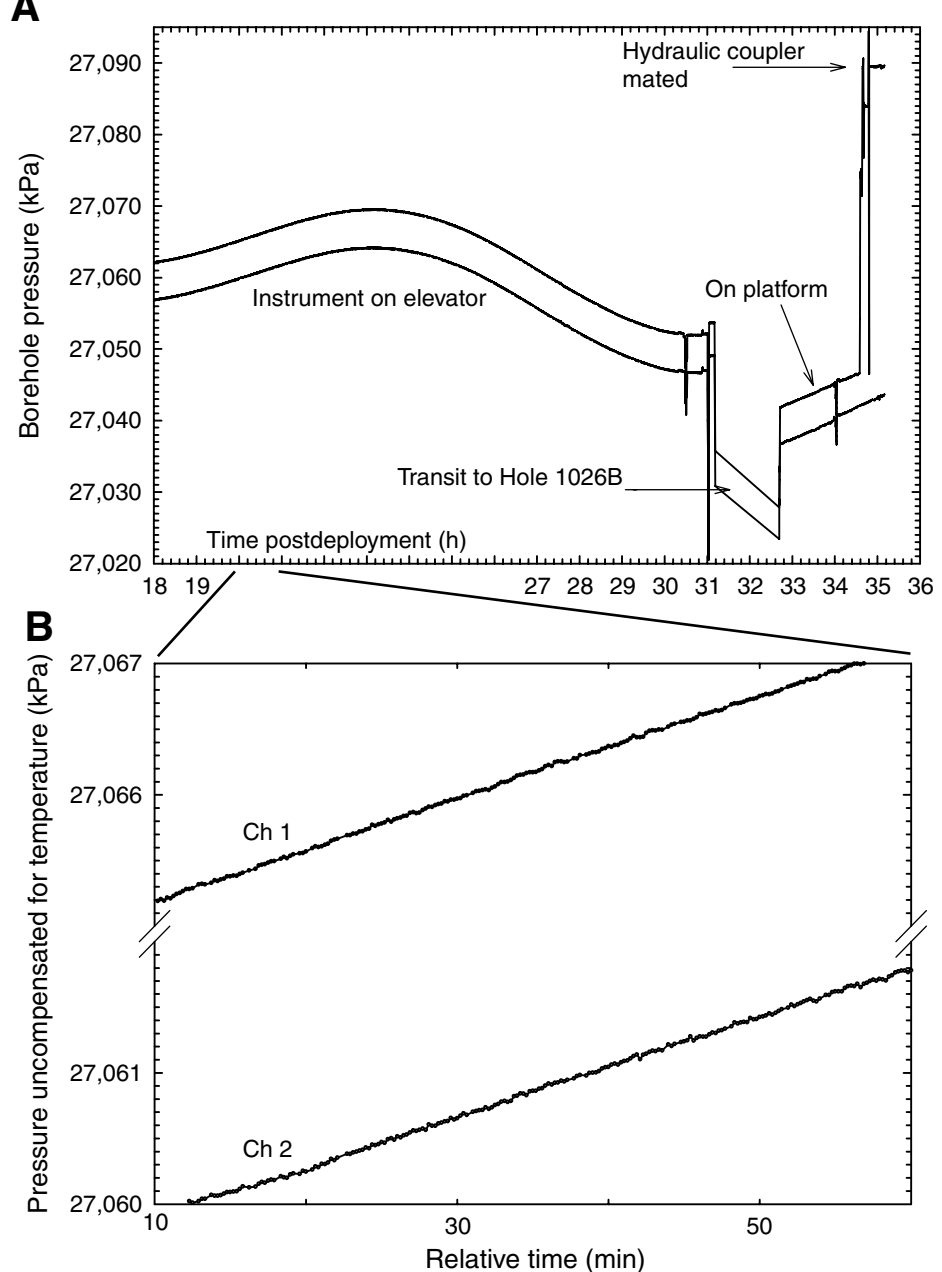
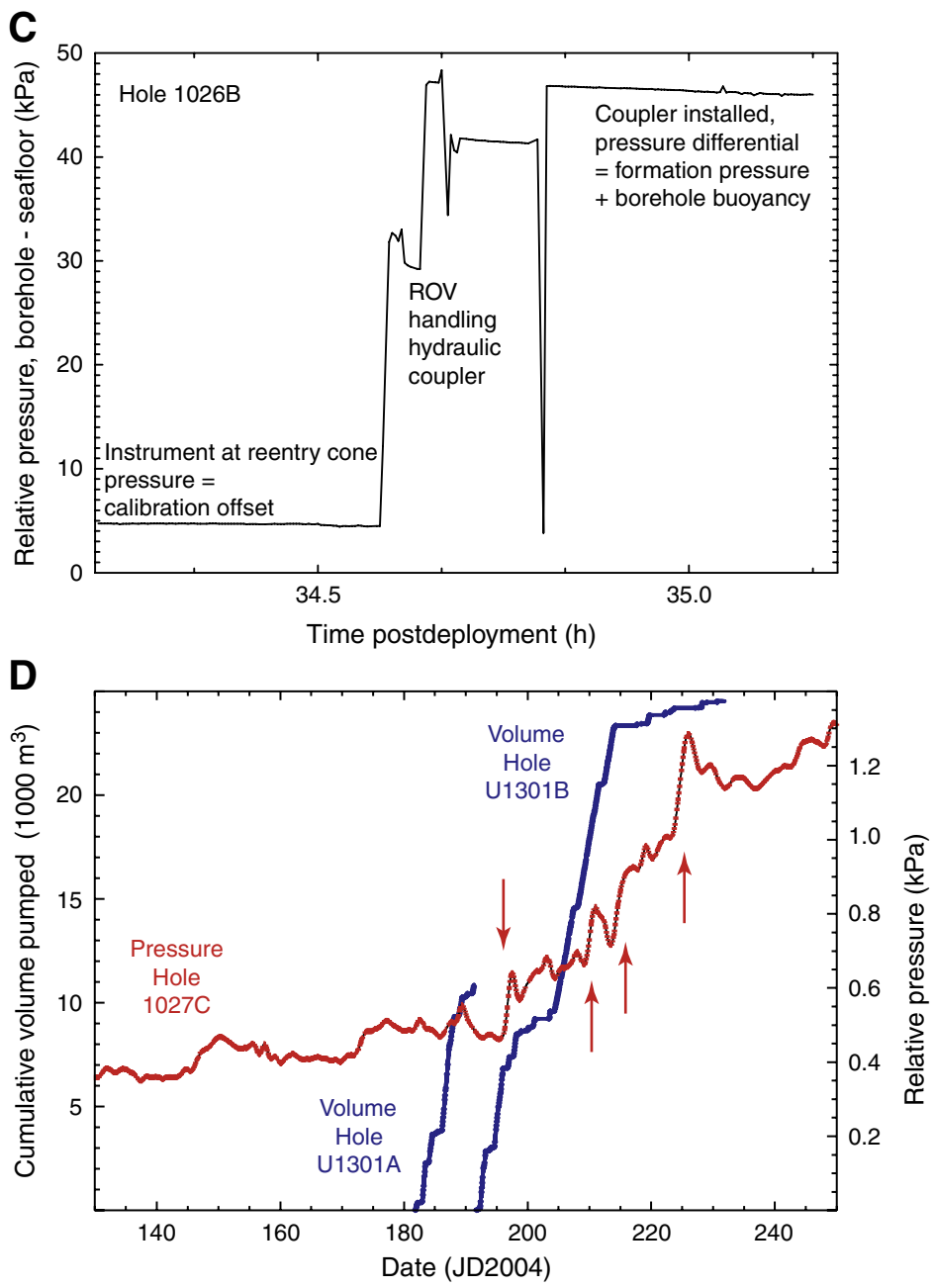
Table T1. Specifications for Expedition 301 CORK pressure sensor and logging instrumentation.

\begin{tabular}{lccc}
\hline \multicolumn{1}{c}{ Hole } & 1026B & U1301A & U1301B \\
\hline Logger channels & 2 & 3 & 4 \\
Bytes/sample & 20 & 28 & 36 \\
Sample rate (s) & 15 & 60 & 60 \\
Memory capacity (MB) & 256 & 256 & 256 \\
Bytes/y (MB) & 42 & 14.7 & 18.9 \\
Estimated download time (min) at 115.2 kbps & 62 & 22 & 28 \\
Power dissipation (mW): & 23 & 23 & 23 \\
SCF & 0.38 & 0.38 & 0.38 \\
RTC + PPC sleep & 88 & 130 & 172 \\
Sampling at 1.5 s & 9.2 & 3.7 & 4.7 \\
Average RTC + PPC & 32.2 & 26.7 & 27.7 \\
Average total & 15.8 & 19.1 & 18.4 \\
Lifetime (y) & & & \\
\hline
\end{tabular}

Notes: $\mathrm{SCF}=$ serial to compact flash. $\mathrm{RTC}=$ real-time clock. $\mathrm{PPC}=$ pressure period counter.

Table T2. Additional general specifications for Expedition 301 CORK pressure sensor and logging instrumentation.

\begin{tabular}{ll}
\hline \multicolumn{1}{c}{ Parameter } & \multicolumn{1}{c}{ Specification } \\
\hline Battery capacity & $30 \mathrm{~A} / \mathrm{h}$ at $7.2 \mathrm{~V}, 4473 \mathrm{~W} / \mathrm{h}$ \\
Communications protocol & $\mathrm{RS}-422$ \\
Communication rates & $4800-230.14 \mathrm{kbps}$ \\
$\begin{array}{l}\text { Download protocols: } \\
\text { Sector based (custom) }\end{array}$ & 512 byte packets \\
Xmodem—cyclic redundancy checking & 128 byte packets \\
Xmodem—checksum & 128 byte packets \\
$\quad$ & \\
Streaming & $<10 \mathrm{ppb}$ at $800 \mathrm{~ms}$ integration time $(1 \mathrm{~Hz}$ sampling $)$ \\
Period measurement noise & $<100 \mathrm{ppb}$ full scale at $800 \mathrm{~ms}$ integration time $(\sim 4 \mathrm{~Pa})$ \\
Relative pressure resolution & $<1 \mathrm{ppm}$ at $400 \mathrm{~ms}$ integration time \\
Temperature period measurement noise & $<1 \mathrm{ppm}(\sim 40 \mathrm{~Pa})$ \\
Absolute pressure accuracy (temperature compensated) & $\sim 4 \mathrm{ppm} \sim 2 \mathrm{~min} / \mathrm{y})$ \\
Clock accuracy & \multicolumn{1}{c}{} \\
\hline
\end{tabular}

Table T3. Tracers injected within CORK systems deployed during Expedition 301.

\begin{tabular}{ccc}
\hline Hole & Tracer & $\begin{array}{c}\text { Concentration of injectate } \\
(\mathrm{mmol} / \mathrm{kg})\end{array}$ \\
\hline 1026B & $\mathrm{Rb}$ & 3.427 \\
& $\mathrm{Gd}$ & 0.100 \\
& $\mathrm{~Tb}$ & 0.005 \\
U1301A & $\mathrm{Cs}$ & 3.673 \\
& $\mathrm{Yb}$ & 0.100 \\
& $\mathrm{Tm}$ & 0.005 \\
$\mathrm{U} 1301 \mathrm{~B}$ & $\mathrm{Dy}$ & 0.001 \\
& $\mathrm{Er}$ & 0.010 \\
& $\mathrm{Ho}$ & 0.100 \\
\hline
\end{tabular}

Note: Tracers were made in dilute $\mathrm{HCl}$ solutions ( $4 \mathrm{~mL}$ of $6 \mathrm{~N}$ subboiled $\mathrm{HCl}$ per liter distilled water). 
Table T4. Rock samples used in flow cell experiments deployed in Expedition 301 CORKs.

\begin{tabular}{|c|c|c|c|}
\hline Hole & Flow cell ID & Mineral & $\begin{array}{l}\text { Size range } \\
(\mathrm{mm})\end{array}$ \\
\hline \multirow[t]{12}{*}{ U1301A } & \multirow[t]{4}{*}{1,2} & Forsterite & $0.60-0.84$ \\
\hline & & Olivine & $0.60-0.84$ \\
\hline & & Fayalite & $0.60-0.84$ \\
\hline & & Hornblende & $0.84-2.00$ \\
\hline & \multirow[t]{4}{*}{3,4} & Basalt glass & $0.84-2.00$ \\
\hline & & Obsidian & $0.84-2.00$ \\
\hline & & Augite & $0.84-2.00$ \\
\hline & & Diopside & $0.60-0.84$ \\
\hline & \multirow{4}{*}{5,6} & Anorthite & $0.84-2.00$ \\
\hline & & Bytownite & $0.60-0.84$ \\
\hline & & K-feldspar (orthoclase) & $0.84-2.00$ \\
\hline & & Apatite & $0.60-0.84$ \\
\hline \multirow[t]{20}{*}{ U1301B } & \multirow[t]{4}{*}{7,8} & Forsterite & $0.60-0.84$ \\
\hline & & Olivine & $0.60-0.84$ \\
\hline & & Augite & $0.60-0.84$ \\
\hline & & Fayalite & $0.60-0.84$ \\
\hline & \multirow[t]{4}{*}{9,10} & Basalt glass & $0.84-2.00$ \\
\hline & & Obsidian & $0.84-2.00$ \\
\hline & & Augite & $0.84-2.00$ \\
\hline & & Magnetite & $0.60-0.84$ \\
\hline & \multirow[t]{4}{*}{11,12} & Anorthite & $0.84-2.00$ \\
\hline & & Bytownite & $0.60-0.84$ \\
\hline & & K-feldspar (orthoclase) & $0.84-2.00$ \\
\hline & & Apatite & $0.60-0.84$ \\
\hline & \multirow[t]{4}{*}{13,14} & Forsterite & $0.60-0.84$ \\
\hline & & Olivine & $0.60-0.84$ \\
\hline & & Augite & $0.60-0.84$ \\
\hline & & Pyrite & $0.30-0.84$ \\
\hline & \multirow{4}{*}{15,16} & Basalt glass & $0.84-2.00$ \\
\hline & & Obsidian & $0.84-2.00$ \\
\hline & & Bytownite & $0.60-0.84$ \\
\hline & & Hematite & $0.30-0.84$ \\
\hline
\end{tabular}

Note: Odd-numbered cells are biotic experiments; even-numbered cells are abiotic controls.

Table T5. Summary of Expedition 301 CORK configurations.

\begin{tabular}{llccc}
\hline & Depth units & Hole 1026B & Hole U1301A & Hole U1301B \\
\hline Total depth of hole & mbsf & 295.2 & 369.7 & 582.8 \\
& msb & 48.1 & 107.5 & 317.6 \\
Total depth of instrument string & mbsf & 215.0 & 290.9 & 531.5 \\
& msb & -32.1 & 28.7 & 266.4 \\
Number of monitored intervals & & 2 & 2 & 3 \\
Upper interval includes only cased hole & & $\mathrm{Y}$ & $\mathrm{Y}$ & $\mathrm{N}$ \\
Number of downhole temperature loggers & & $1-\mathrm{A}, 1-\mathrm{O}$ & $4-\mathrm{A}, 2-\mathrm{O}$ & $11-\mathrm{A}, 3-\mathrm{O}$ \\
Number of downhole OsmoSamplers* & 3 & 4 & 6 \\
Initial number of CORK head OsmoSamplers & & 1 & 1 & 3 \\
\hline
\end{tabular}

Notes: $\mathrm{mbsf}=$ meters below sea floor, $\mathrm{msb}=$ meters subbasement. Hole $1026 \mathrm{~B}$ achieved a total depth of 295.2 mbsf during Leg 168 , but much of the open hole collapsed and a metal liner (drill pipe) was installed to maintain a hydraulic connection with the formation. This liner extends up into casing, so there is no actual "open hole" in Hole 1026B. Instrument string extends from upper plug in CORK head to the end of the lower end of the sinker bar. $\mathrm{A}=$ Antares, $\mathrm{O}=$ Onset. * = includes gas-tight, acid addition, tracer injection, and microbiological OsmoSampler systems. All except the two samples monitoring the second interval in Hole U1301B were recovered during September 2004 dive operations. 
Table T6. Summary of autonomous temperature logger deployment with Expedition 301 CORK systems.

\begin{tabular}{|c|c|c|c|}
\hline Hole & Data logger & Position on sensor string & $\begin{array}{l}\text { Depth } \\
\text { (mbsf) }\end{array}$ \\
\hline \multirow[t]{2}{*}{ 1026B } & O597 & Bottom of middle OsmoSampler & 205.5 \\
\hline & $\mathrm{A} 005$ & Bottom of deepest $\left(3^{\text {rd }}\right)$ OsmoSampler & 210.5 \\
\hline \multirow[t]{6}{*}{ U1301A } & A006 & $52 \mathrm{~m}$ down lower Spectra section & 266 \\
\hline & $\mathrm{A} 003$ & $57 \mathrm{~m}$ down lower Spectra section & 270.8 \\
\hline & O595 & Bottom of top OsmoSampler & 275.5 \\
\hline & A001 & Middle of second OsmoSampler & 279.3 \\
\hline & O596 & Bottom of third OsmoSampler & 283 \\
\hline & A002 & Bottom of deepest $\left(4^{\text {th }}\right)$ OsmoSampler & 286.8 \\
\hline \multirow[t]{14}{*}{ U1301B } & $\mathrm{A} 010$ & $270 \mathrm{~m}$ in upper Spectra section & 266 \\
\hline & O599 & $294 \mathrm{~m}$ in upper Spectra section & 290 \\
\hline & 0600 & $318 \mathrm{~m}$ in upper Spectra section & 314 \\
\hline & O601 & $342 \mathrm{~m}$ in upper Spectra section & 338 \\
\hline & $\mathrm{A} 011$ & $365 \mathrm{~m}$ in upper Spectra section & 361 \\
\hline & $\mathrm{A} 012$ & $10 \mathrm{~m}$ in middle Spectra section & 383 \\
\hline & $\mathrm{A} 014$ & $30 \mathrm{~m}$ in middle Spectra section & 402 \\
\hline & A016 & $50 \mathrm{~m}$ in middle Spectra section & 421 \\
\hline & $\mathrm{A} 017$ & $70 \mathrm{~m}$ in middle Spectra section & 440 \\
\hline & $\mathrm{A} 018$ & $90 \mathrm{~m}$ in middle Spectra section & 459 \\
\hline & $\mathrm{A} 020$ & $15 \mathrm{~m}$ in lowest Spectra section & 483.5 \\
\hline & A009 & Bottom of top OsmoSampler & 510 \\
\hline & A019 & Bottom of $4^{\text {th }}$ OsmoSampler & 521.5 \\
\hline & $\mathrm{A} 007$ & Bottom of deepest $\left(6^{\text {th }}\right)$ OsmoSampler & 528 \\
\hline
\end{tabular}

Notes: A\#\#\# = Antares 16-bit loggers, programmed for logger maximum of 65,000 samples at $1 \mathrm{~h}$ intervals, S/N 1857\#\#\#. O\#\#\# = Onset 12 bit loggers, programmed for logger maximum of 43,000 samples at $1.5 \mathrm{~h}$ intervals. Strings in Holes $1026 \mathrm{~B}$ and U1301A used two sections of Spectra rope, one between top seal plug and intermediate sinker bar, the other between intermediate sinker bar and bottom seal plug. A third section of Spectra was added in Hole U1301B, hanging below lower seal plug. Positions of top and bottom seal plugs are well determined relative to seafloor, but the slack built into the sensor strings ( $2 \mathrm{~m}$ in Holes 1026B and U1301A; $6 \mathrm{~m}$ in Hole U1301B) is assumed to be taken up evenly in Spectra between intermediate sinker bar and lower seal plug. Therefore, uncertainty in position below seafloor is greater for sensors in lower section of Spectra rope. 